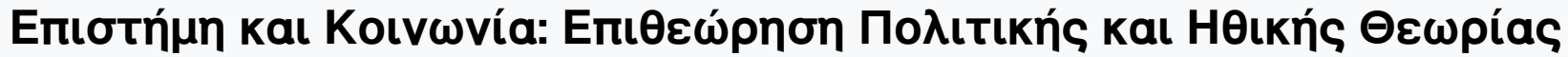

Tó 27 (2011)

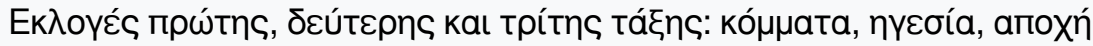

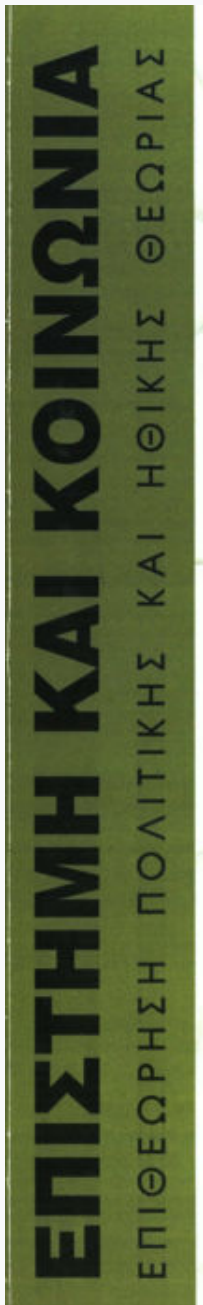

http://www.media.uoa.gr/sas

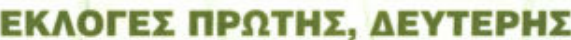

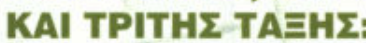 KOMMATA, HГEEIA, АПOXH}

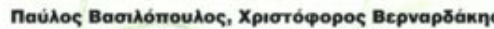

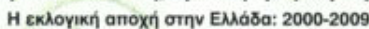

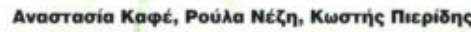

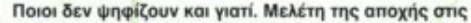

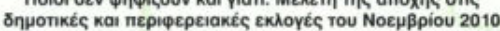

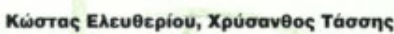

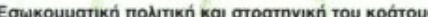

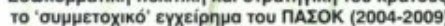

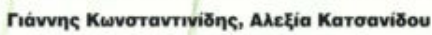

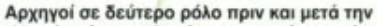

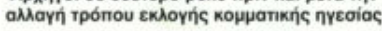

ITaúpos Iкpivns

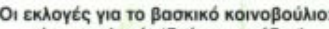

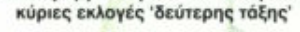

rewipyıes Bגáxxos

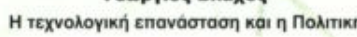

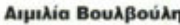

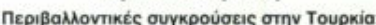

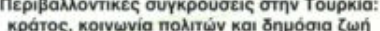

\section{Bàıı Apavitou}

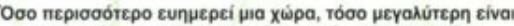

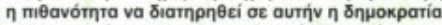

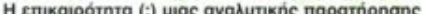

BaơıAıkń rewpyıáðou

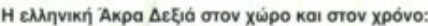

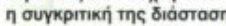

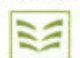

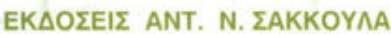

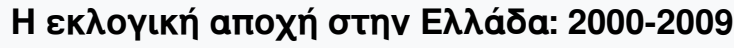

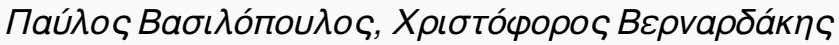

doi: $10.12681 /$ sas. 804

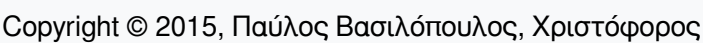
Bepvapঠáknৎ

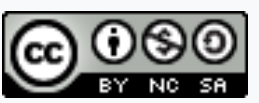

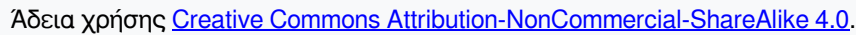

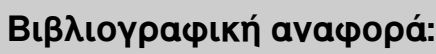

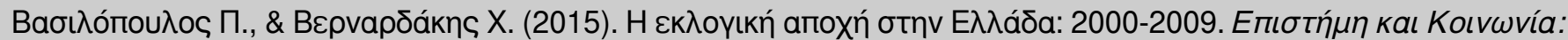

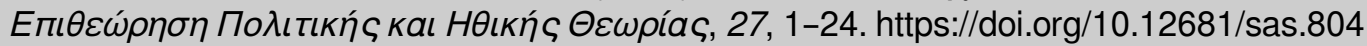




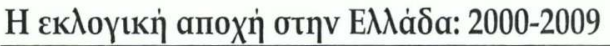

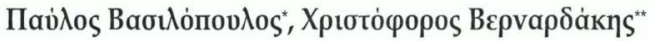

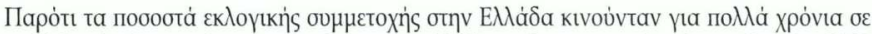

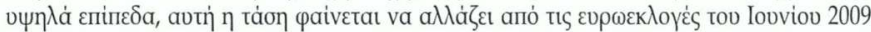

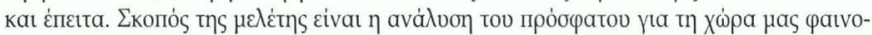

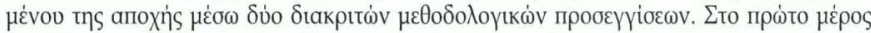

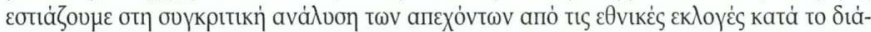

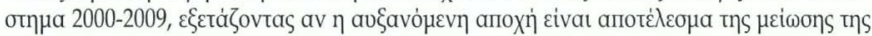

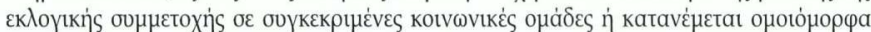

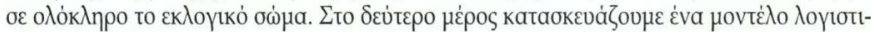

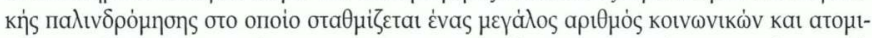

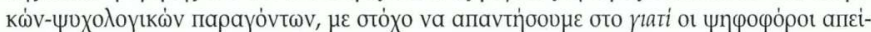

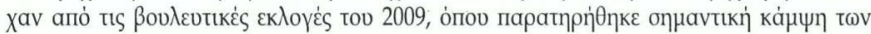

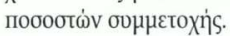

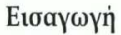

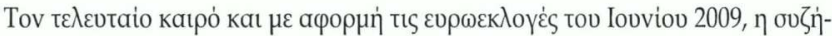

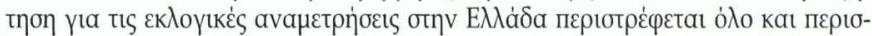

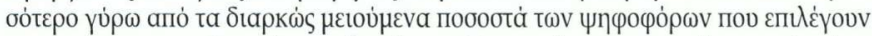

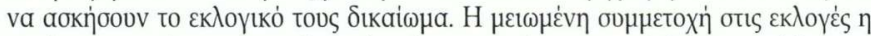
опоіа катаүра́)

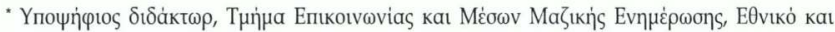

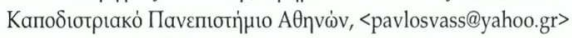

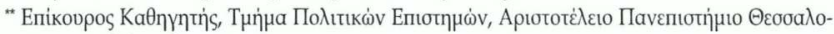
vikns, <xvernard@gmail.com>

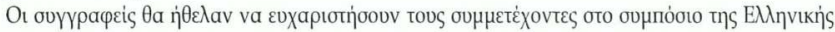

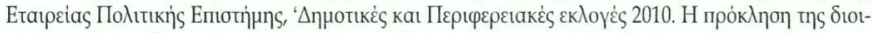

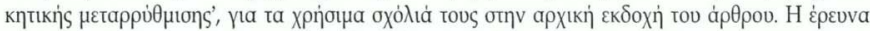

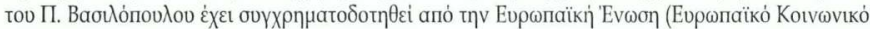

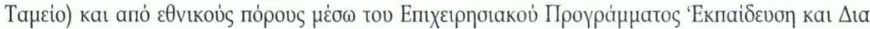

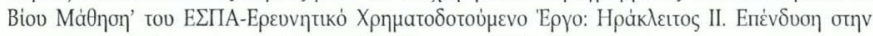

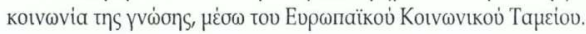




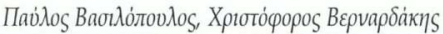

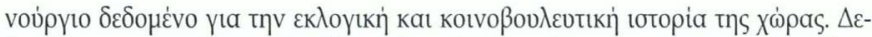

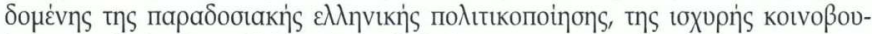

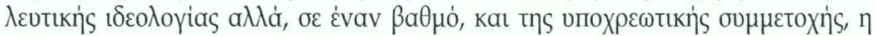

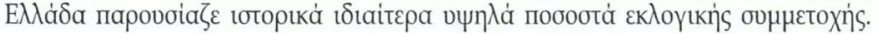

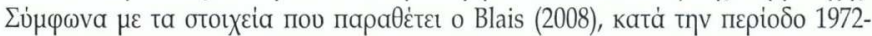

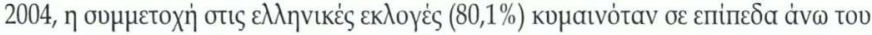

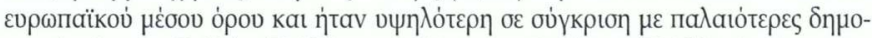

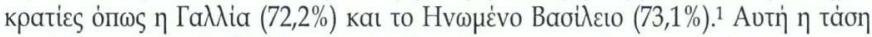

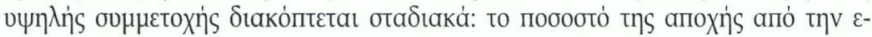

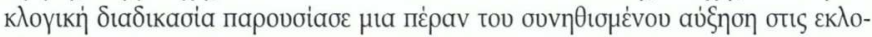

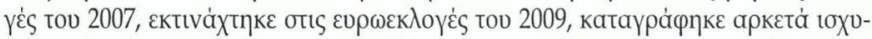

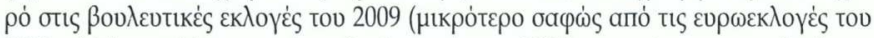

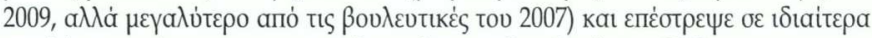

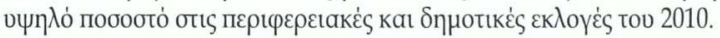

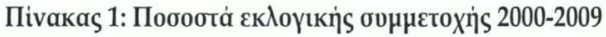

\begin{tabular}{|c|c|c|}
\hline Етоৎ & 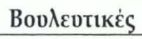 & 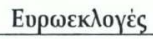 \\
\hline 2000 & 74,96 & \\
\hline 2004 & 76,49 & 63,22 \\
\hline 2007 & 74,14 & \\
\hline 2009 & 70,92 & 52,54 \\
\hline
\end{tabular}

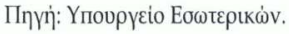

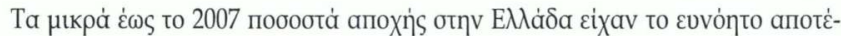

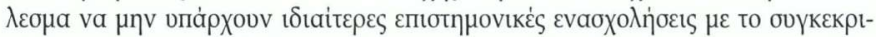

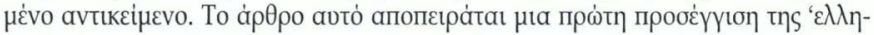

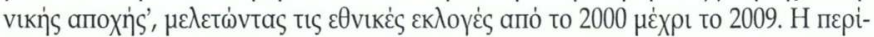

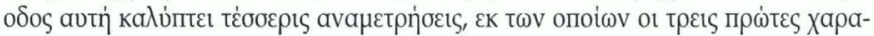

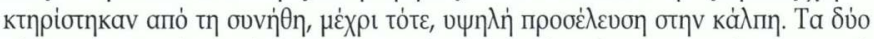

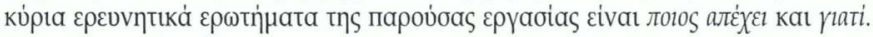

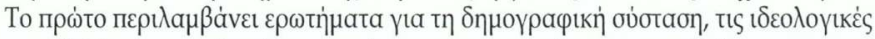

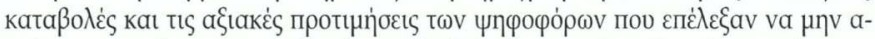

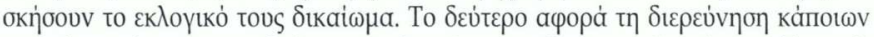

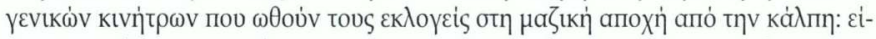

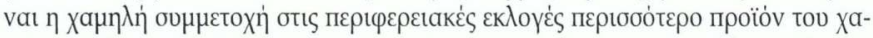

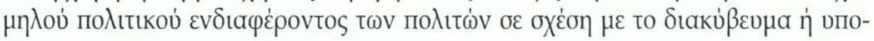




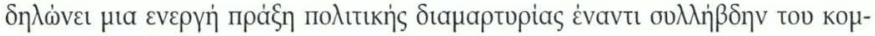

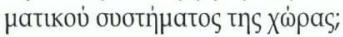

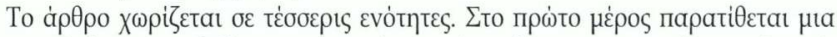

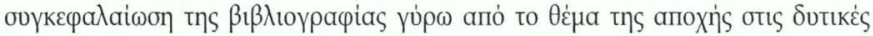

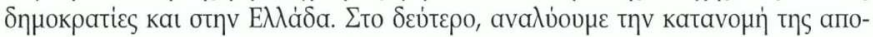

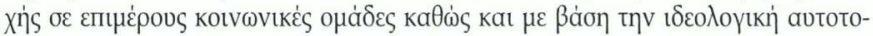

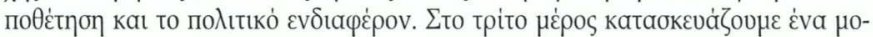

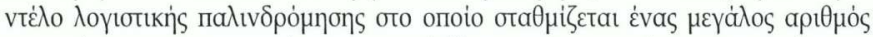

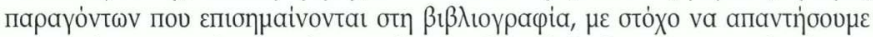

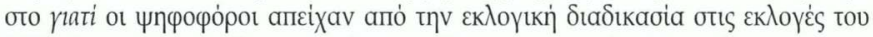

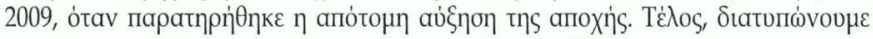

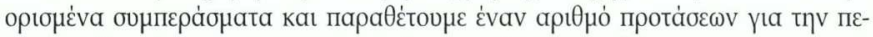

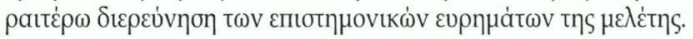

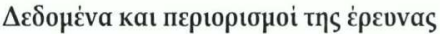

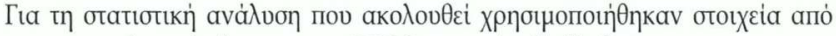

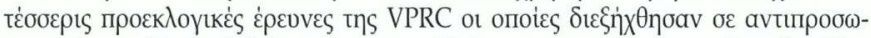

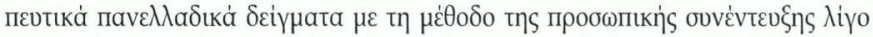

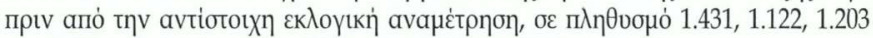

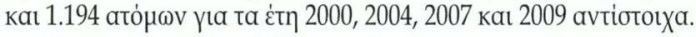

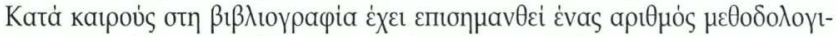

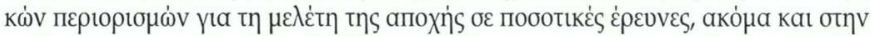

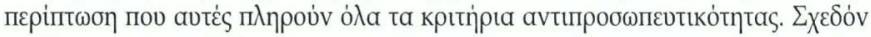

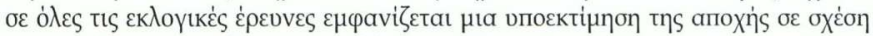

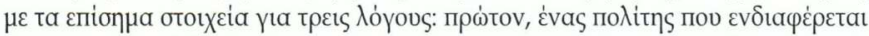

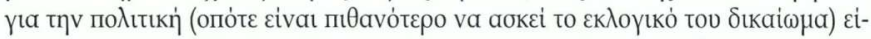

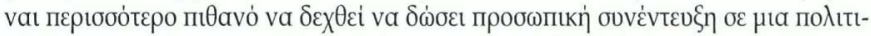

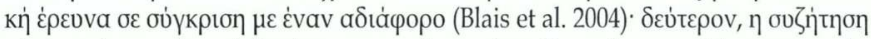

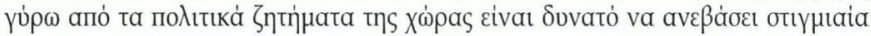

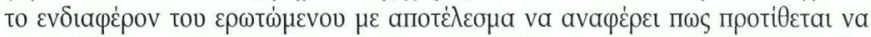

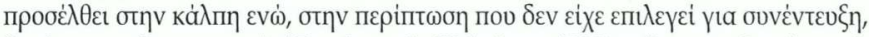

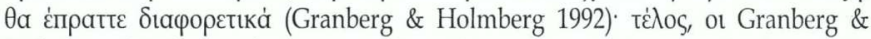

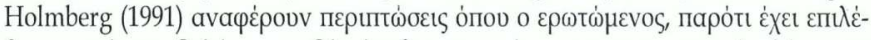

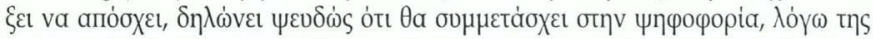

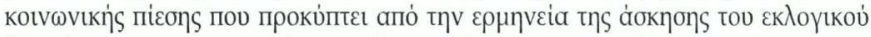

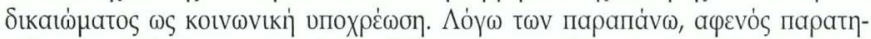

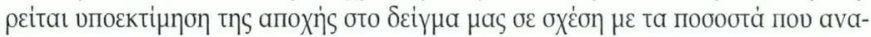

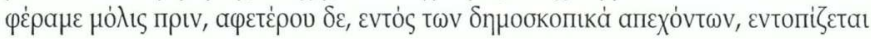




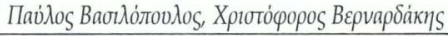

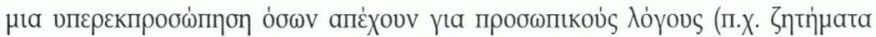

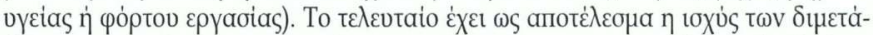

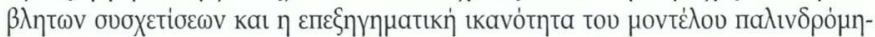

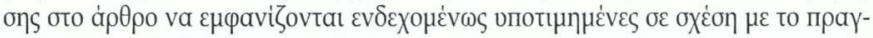

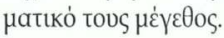

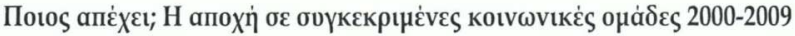

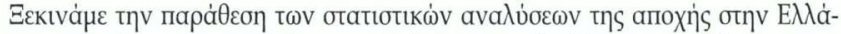

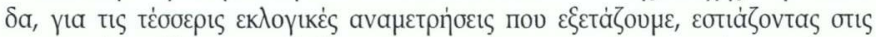

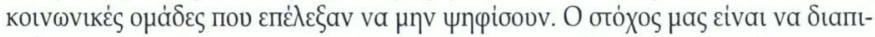

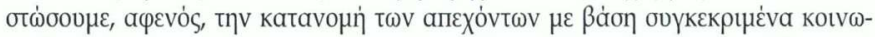

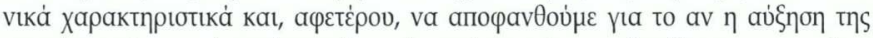

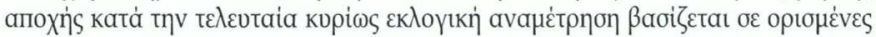

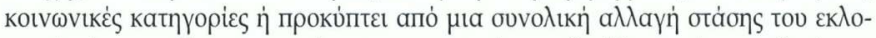

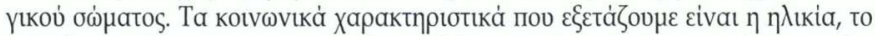

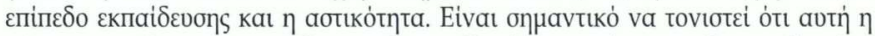

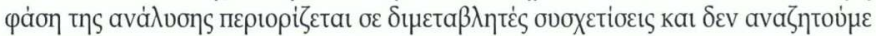

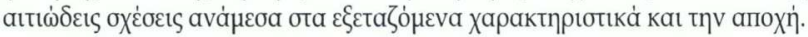

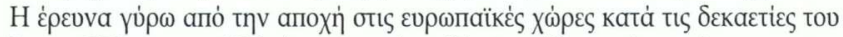

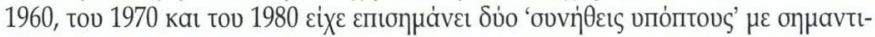

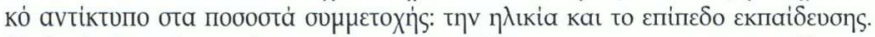

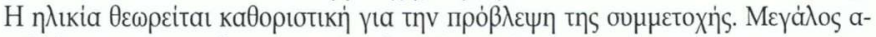

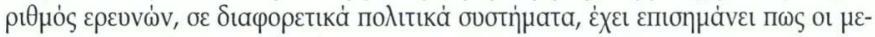

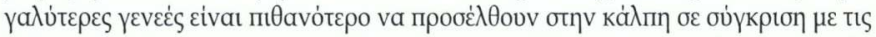

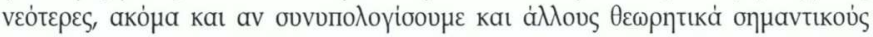
пара́yovtes (Topf 1995, Franklin 1996, Blais et al. 2002, Aarts \& Wessels 2005,

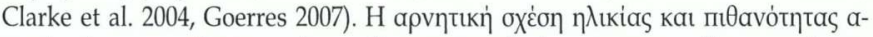

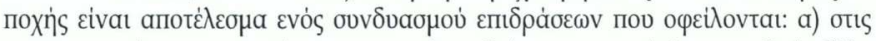

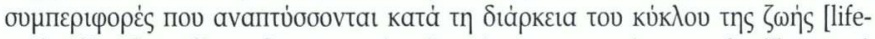

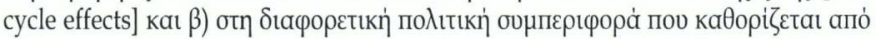

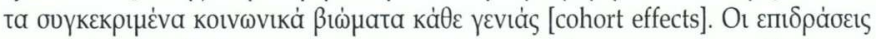

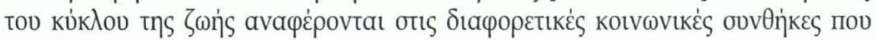

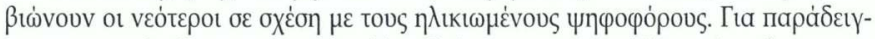

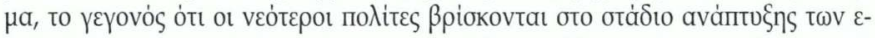

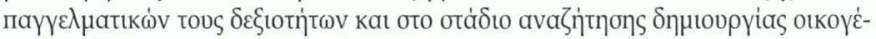

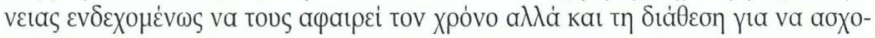

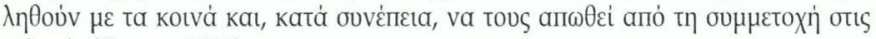

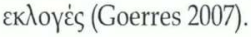




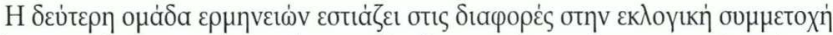

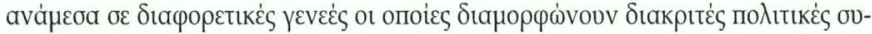

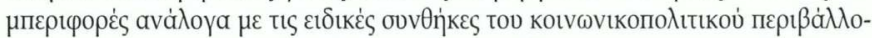

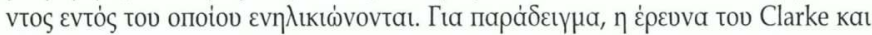

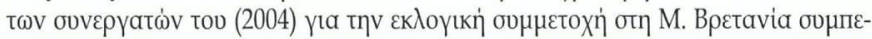

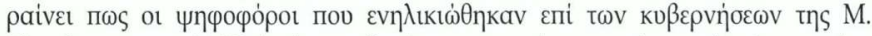

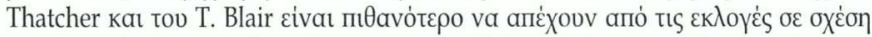

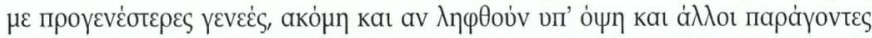

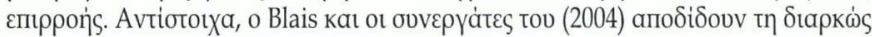

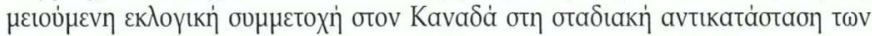

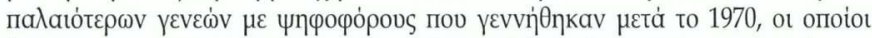

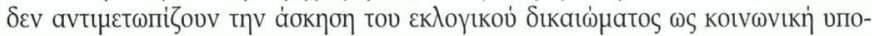

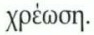

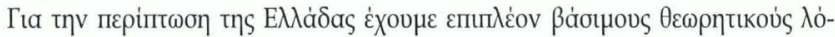

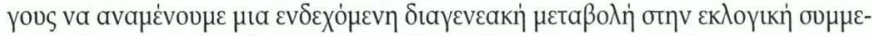

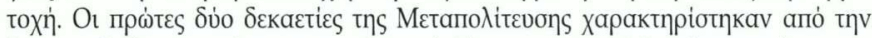

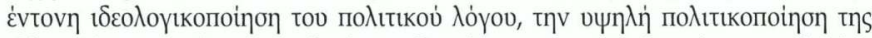

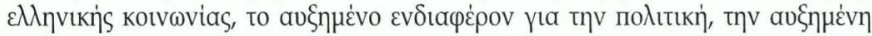

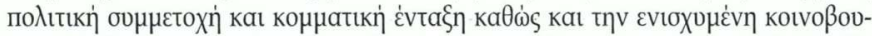

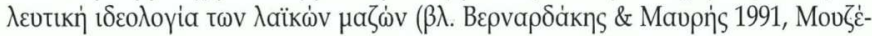

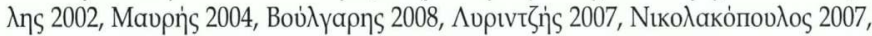

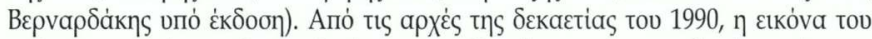

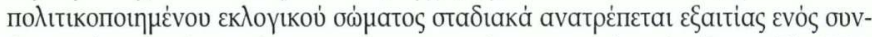

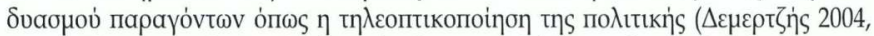

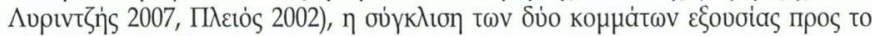

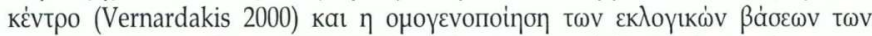

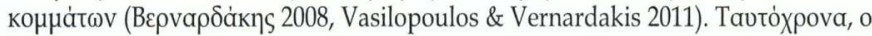

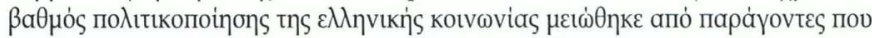

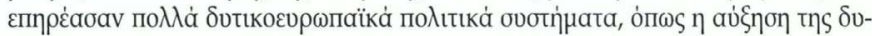

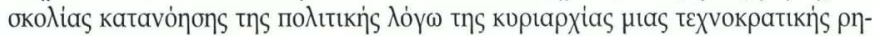

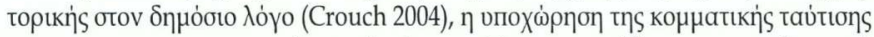

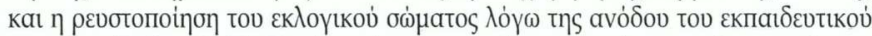

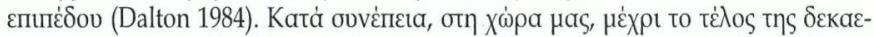

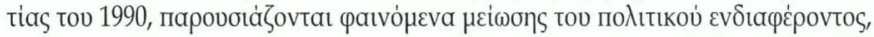

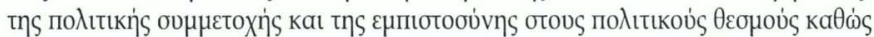

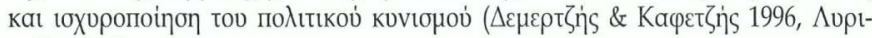

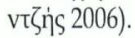




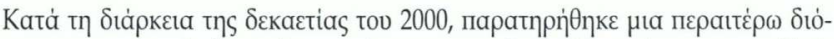

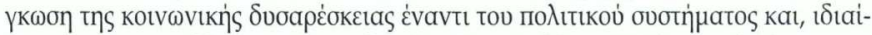

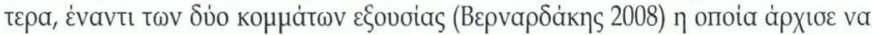

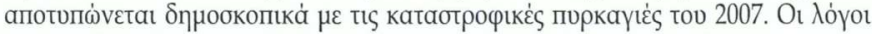

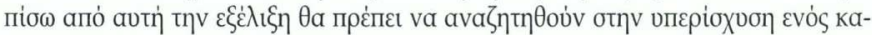

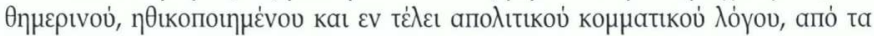

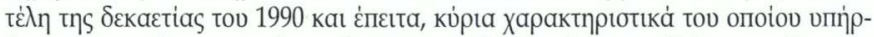

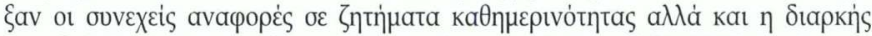

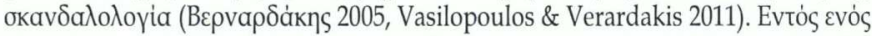

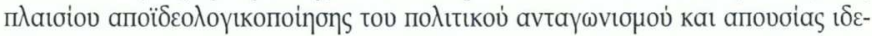

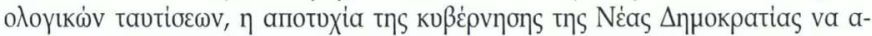

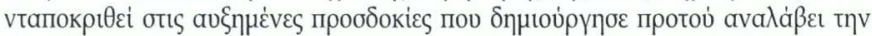

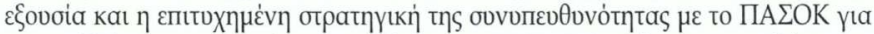

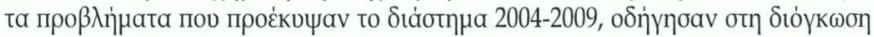

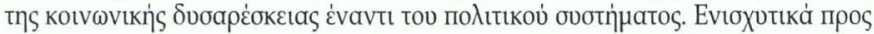

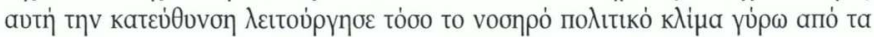

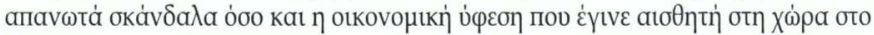

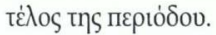

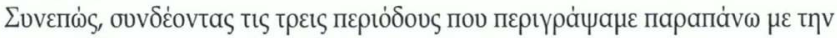

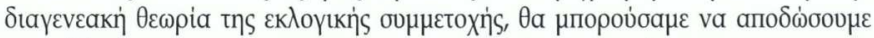

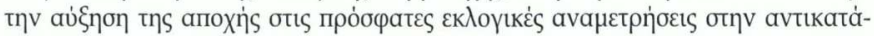

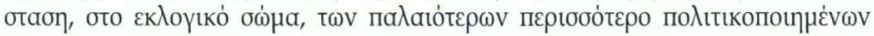

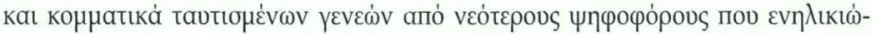

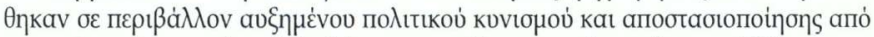

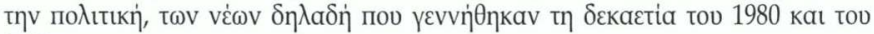
1990.

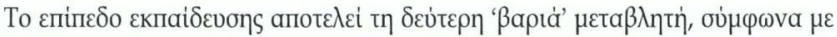

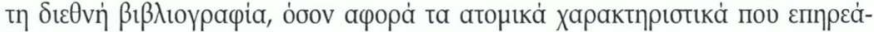

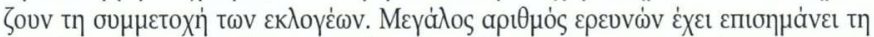

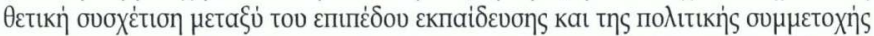

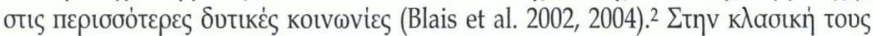

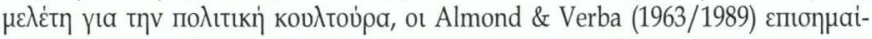

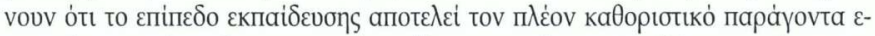

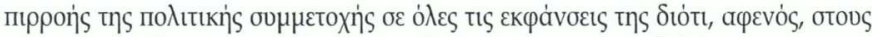

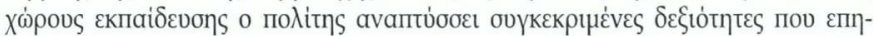

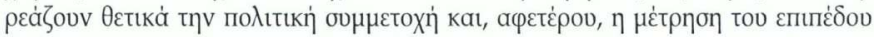

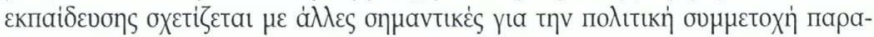

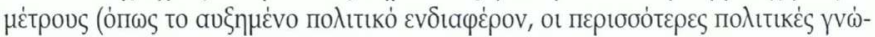




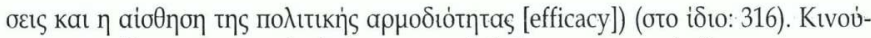

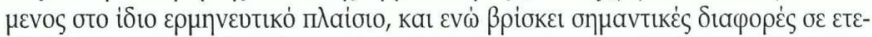

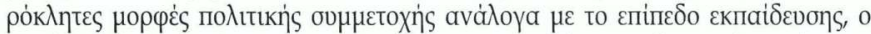

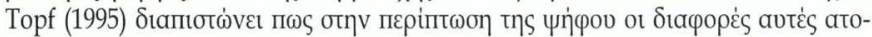

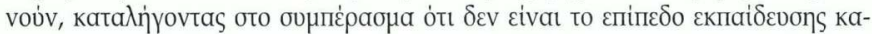

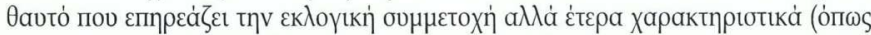

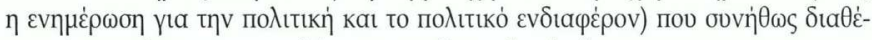

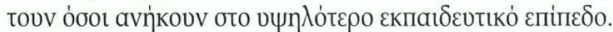

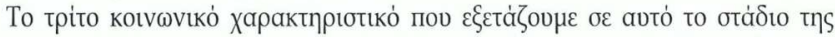

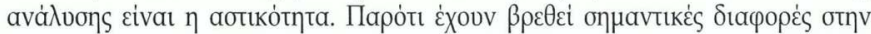

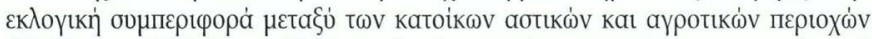

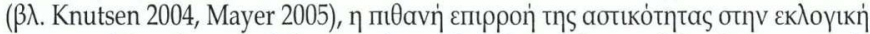

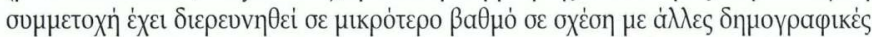

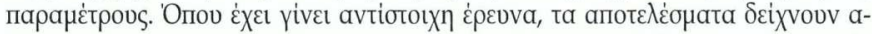

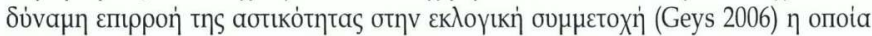

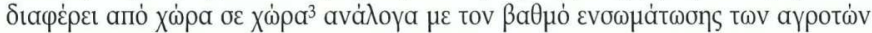

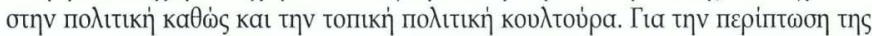

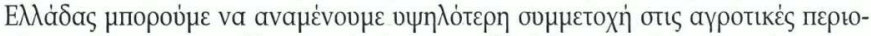

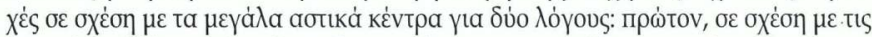

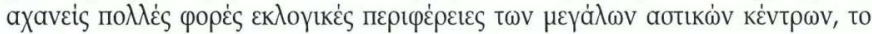

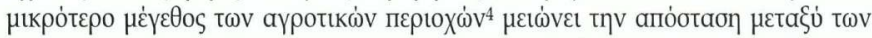

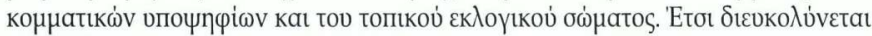
$\eta$ а

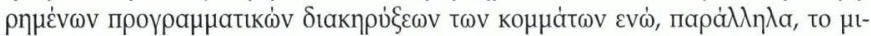

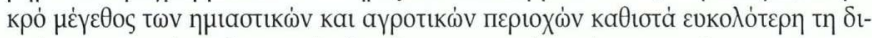

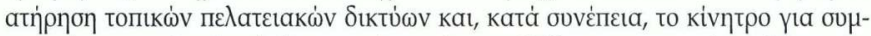

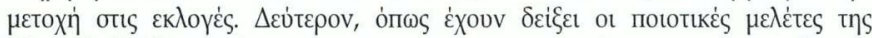

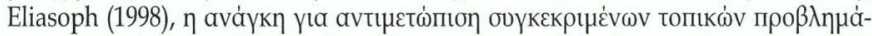

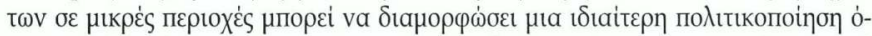

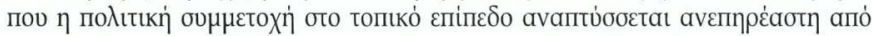

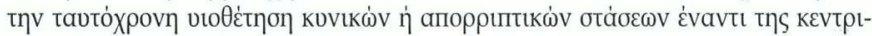

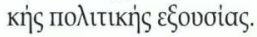

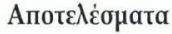

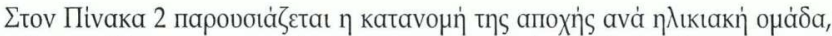

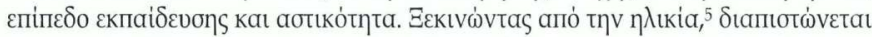

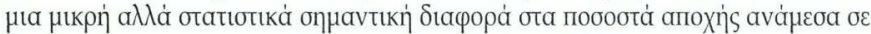

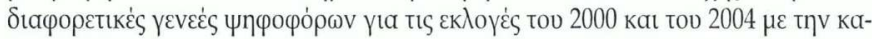




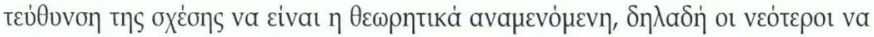

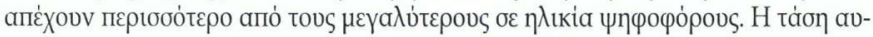

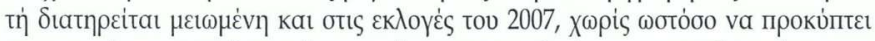

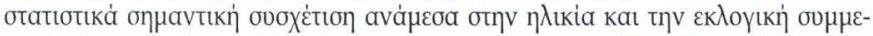

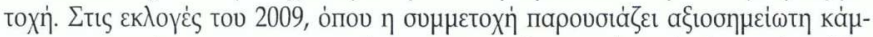

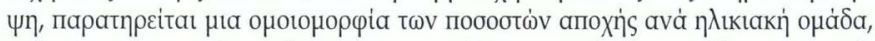

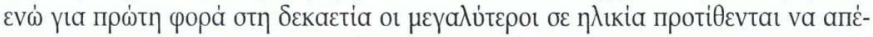

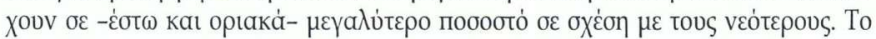

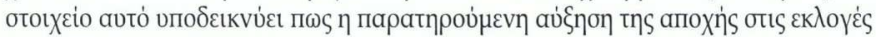

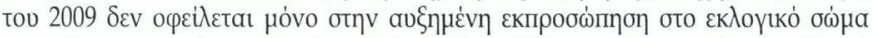

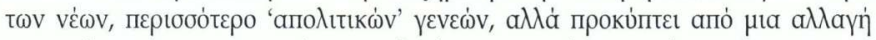

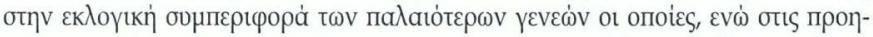

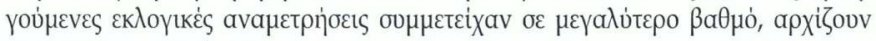
va aாобтđбเопоเов́vtat.

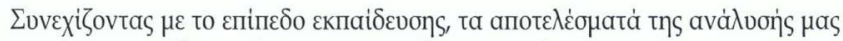

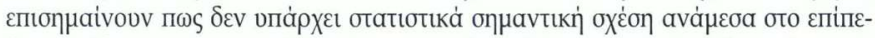

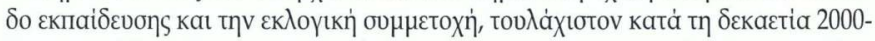

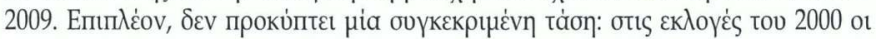

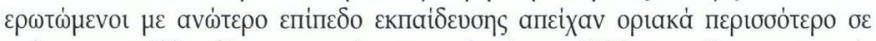

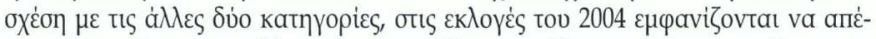

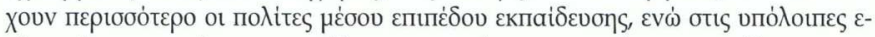

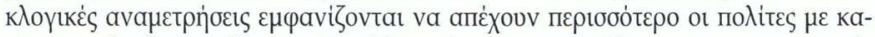

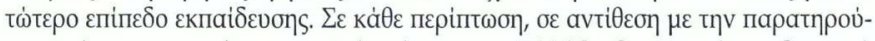

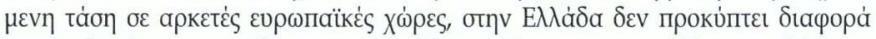

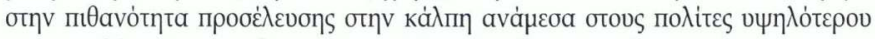

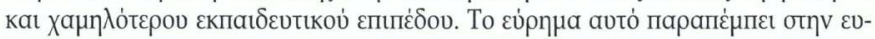

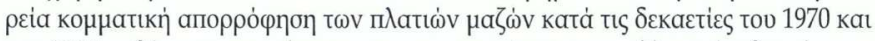

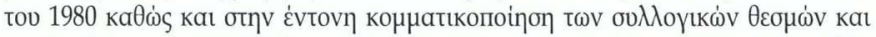

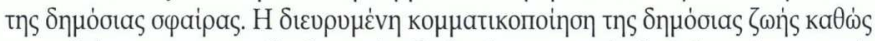

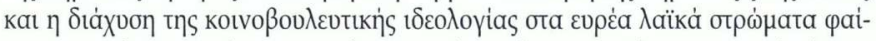

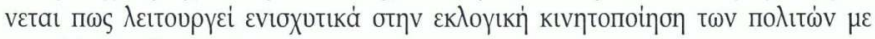

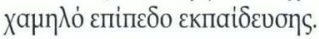

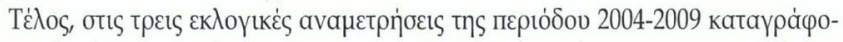

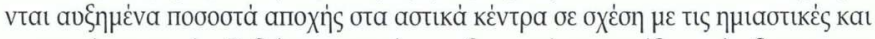

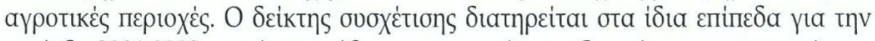

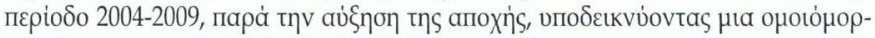

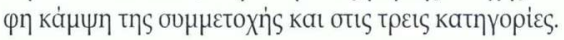




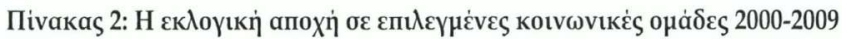

\begin{tabular}{|c|c|c|c|c|}
\hline & 2000 & 2004 & 2007 & 2009 \\
\hline \multicolumn{5}{|l|}{ НАıкіа } \\
\hline $18-34$ & 5,5 & 3,5 & 9,3 & 8,2 \\
\hline $35-54$ & 5,2 & 1,3 & 6,2 & 10,1 \\
\hline $55+$ & 2,4 & 1,5 & 6,5 & 10,4 \\
\hline 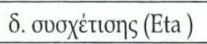 & $\eta=0.07^{\star \star}$ & $\eta=0.07^{* *}$ & $\eta=0.05$ & $\eta=0.03$ \\
\hline \multicolumn{5}{|c|}{ 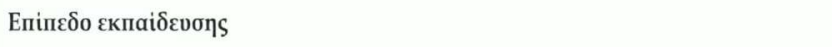 } \\
\hline Katஸ்teро & 3,5 & 2,0 & 7,9 & 9,6 \\
\hline Mغ̇øo & 4,5 & 2,9 & 6,3 & 9,7 \\
\hline Avஸ்тยро & 5,3 & 2,3 & 7,5 & 7,9 \\
\hline 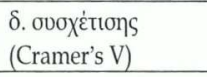 & $V=0.04$ & $\mathrm{~V}=0.06$ & $V=0.03$ & $\mathrm{~V}=0.02$ \\
\hline \multicolumn{5}{|l|}{ Абтเко́тทта } \\
\hline Ađtıкá & 5,5 & 3,1 & 9,2 & 11,8 \\
\hline Ннıаotıка́ & 4,2 & 0,5 & 6,7 & 5,3 \\
\hline Аүротика่ & 3,5 & 0,4 & 3,0 & 5,1 \\
\hline 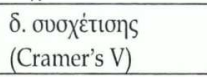 & $\mathrm{v}=0.05$ & $v=0.10^{* *}$ & $\mathrm{v}=0.10^{* *}$ & $v=0.11^{* * *}$ \\
\hline
\end{tabular}

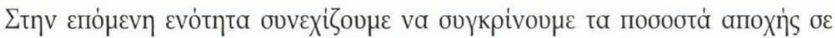

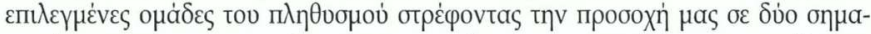

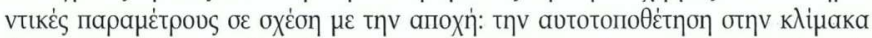

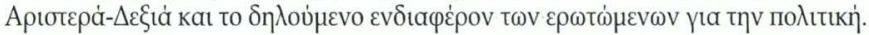

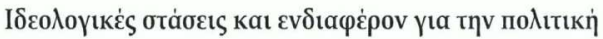

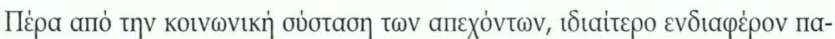

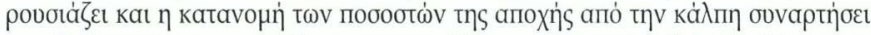

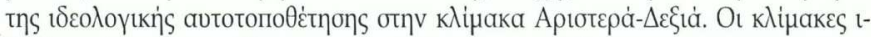

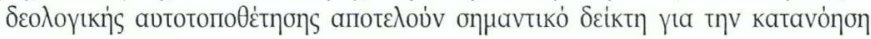




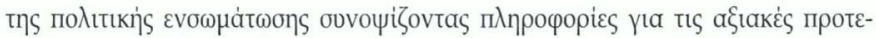

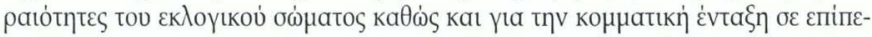

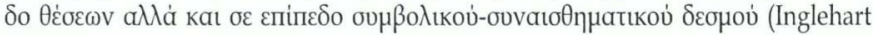

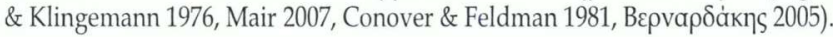

Гра்

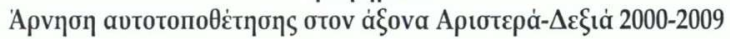

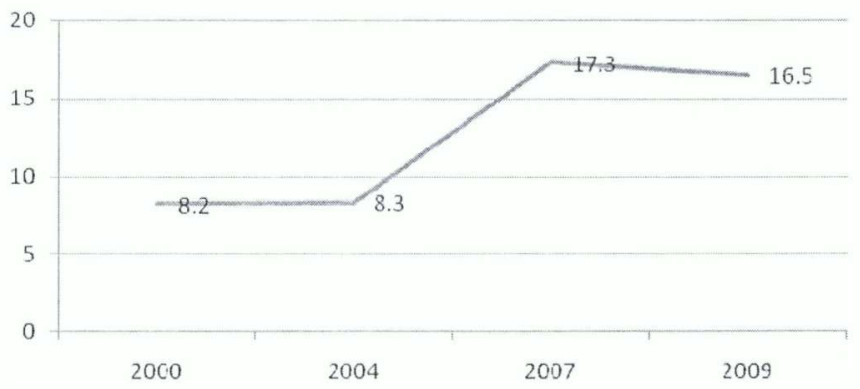

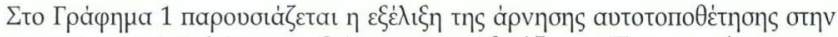

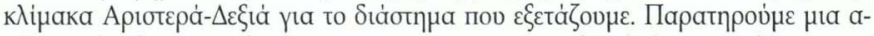

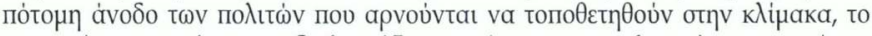

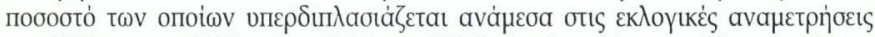

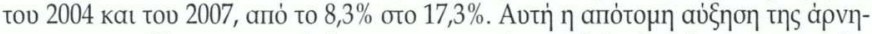

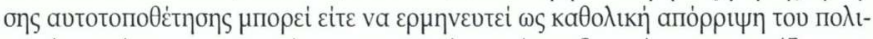

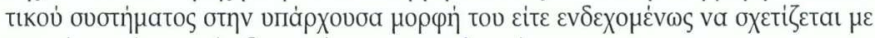

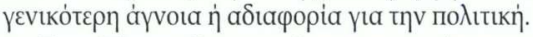

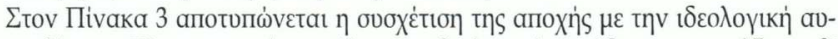

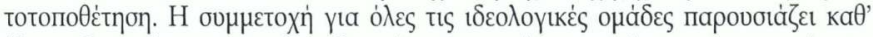

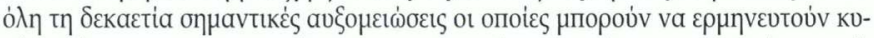

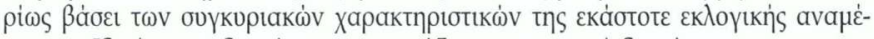

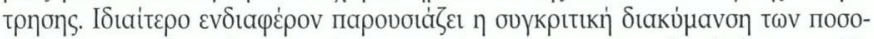

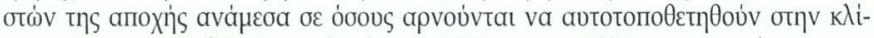

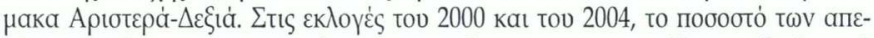

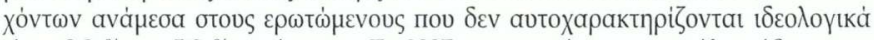

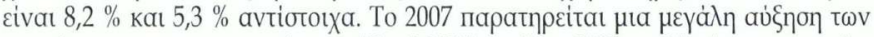

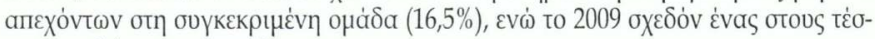

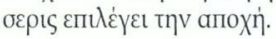




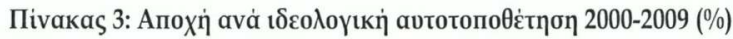

\begin{tabular}{|c|c|c|c|c|}
\hline & 2000 & 2004 & 2007 & 2009 \\
\hline Aрtотера் & 3,7 & 3,5 & 6,9 & 5,9 \\
\hline Кеvтроартотера́ & 5,6 & 1,7 & 4,9 & 5,3 \\
\hline Ке́vтро & 3,4 & 2,3 & 6,7 & 6,6 \\
\hline 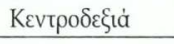 & 3,6 & 1,3 & 3,9 & 7,5 \\
\hline$\Delta \varepsilon \xi \hat{\imath} \dot{\alpha}$ & 4,6 & 0,8 & 3,2 & 6,1 \\
\hline 'Арvๆ & 8,2 & 5,3 & 16,5 & 24,6 \\
\hline
\end{tabular}

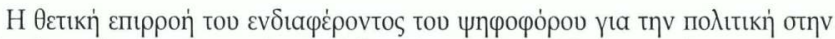

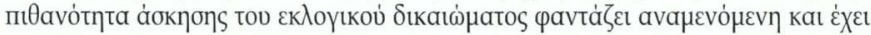

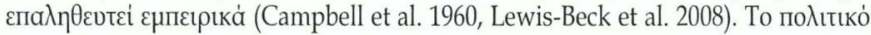

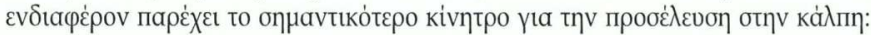

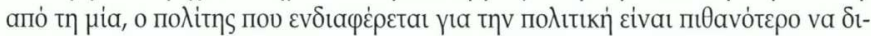

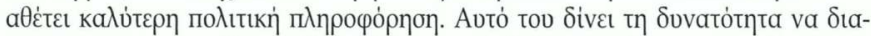

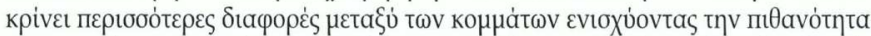

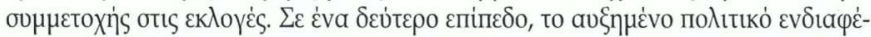

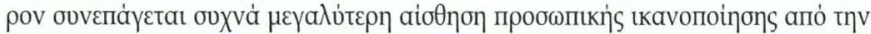

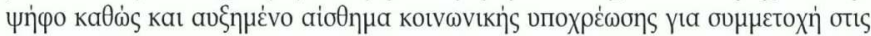

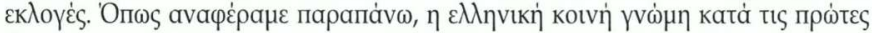

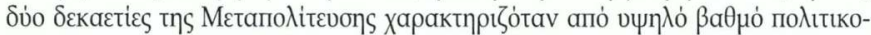

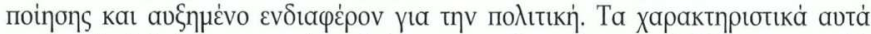

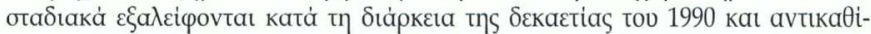

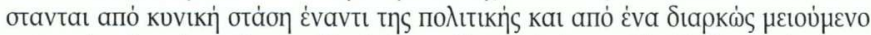

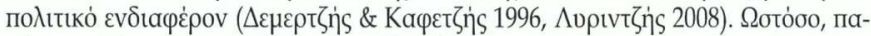

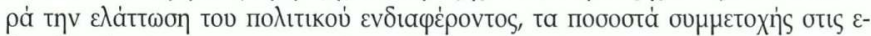

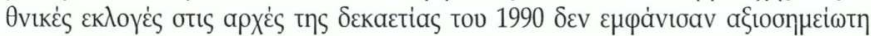

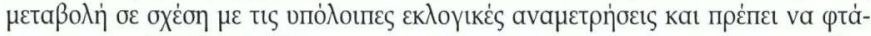

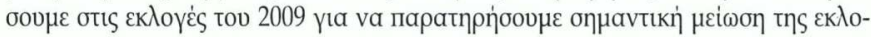

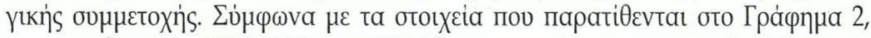

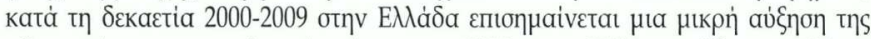

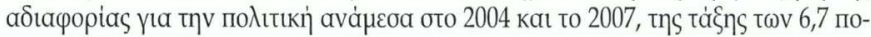

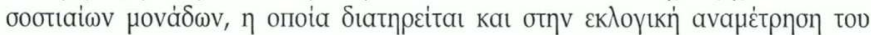
2009. 


\section{Гра́фпна 2:}

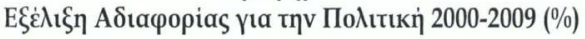

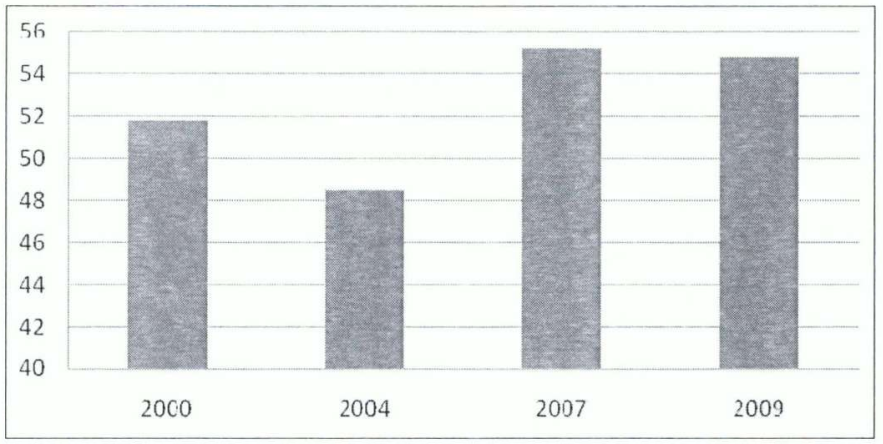

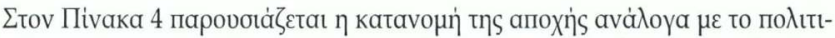

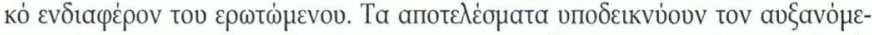

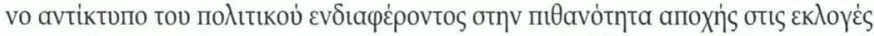

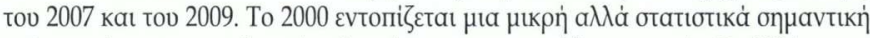

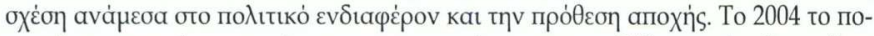

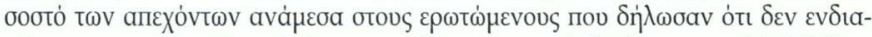

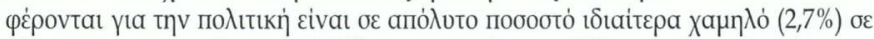

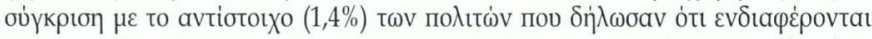

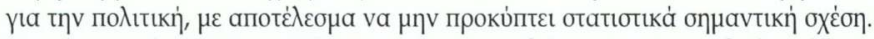

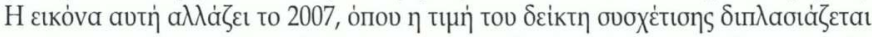

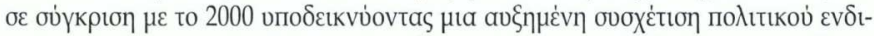

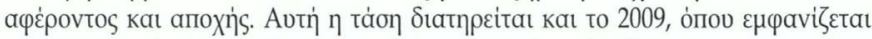

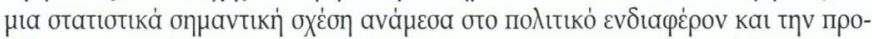

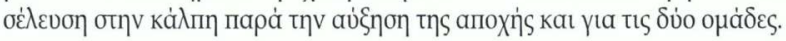

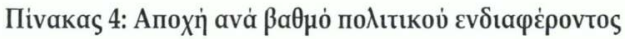

\begin{tabular}{|c|c|c|c|c|}
\hline & 2000 & 2004 & 2007 & 2009 \\
\hline 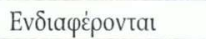 & 2,9 & 1,4 & 3,1 & 5,3 \\
\hline 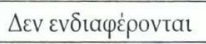 & 5,9 & 2,7 & 10,4 & 12,4 \\
\hline 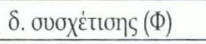 & $0,07^{* \star}$ & 0,05 & $0,14^{\star * *}$ & $0,12^{\text {** }}$ \\
\hline
\end{tabular}

${ }^{*}=\mathrm{p}<0,1,{ }^{* *}=\mathrm{p}<0,05,{ }^{* * *}=\mathrm{p}<0,001$ 


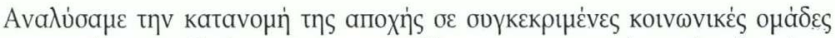

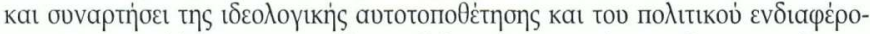

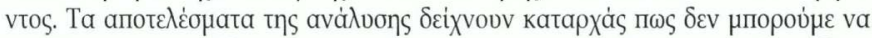

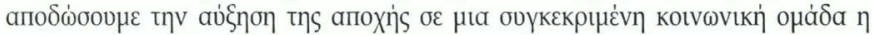

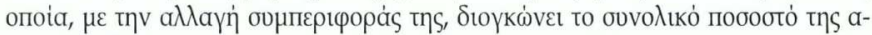

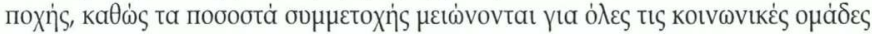

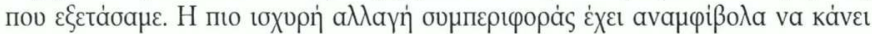

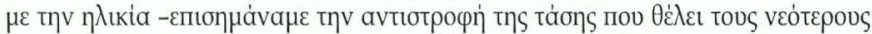

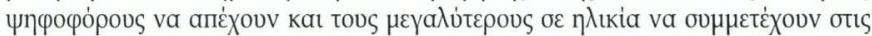

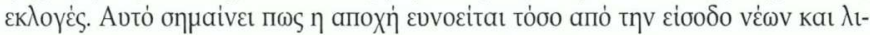

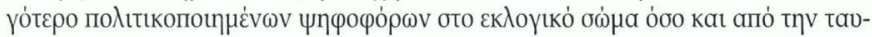

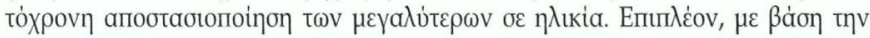

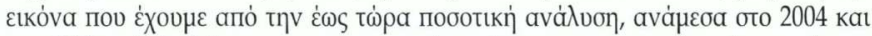

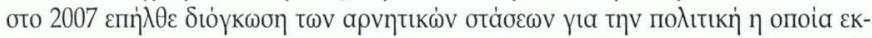

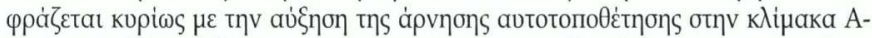

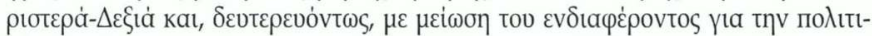

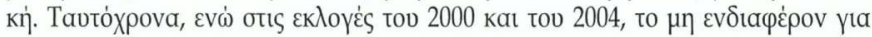

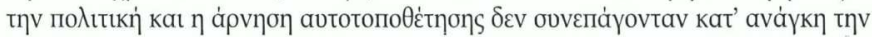

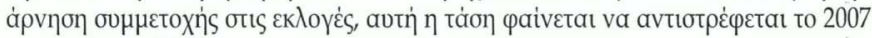

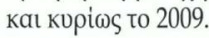

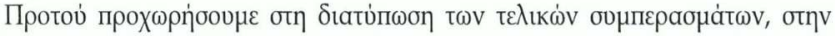

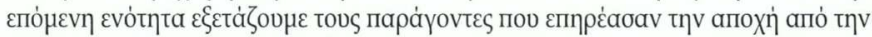

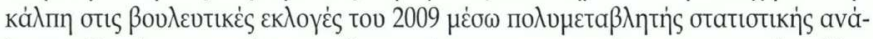

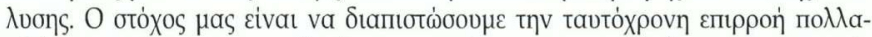

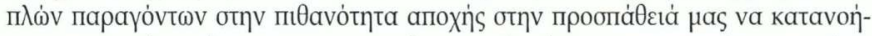

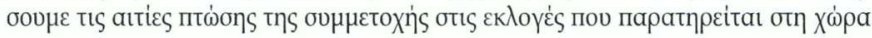
uaş.

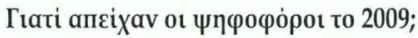

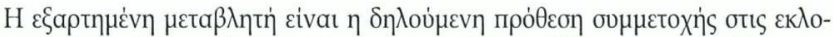

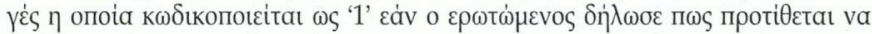

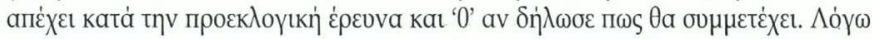

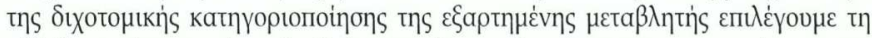

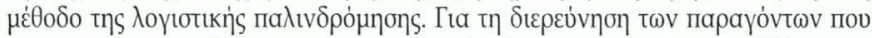

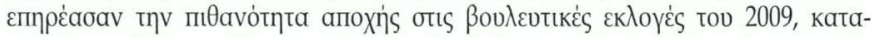

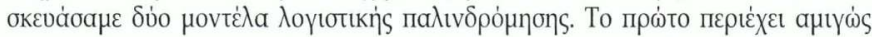

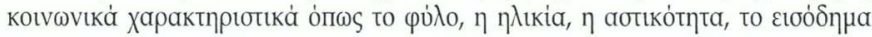

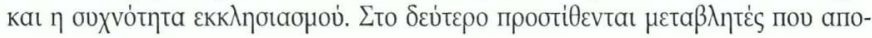




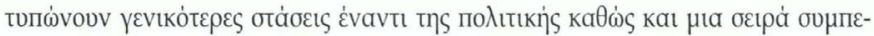

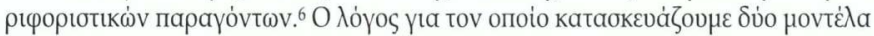

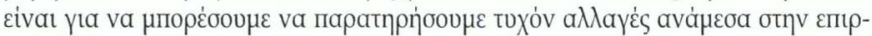

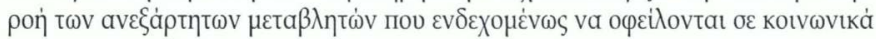

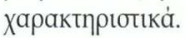

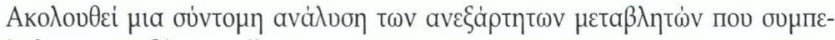

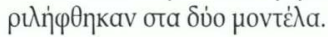

\section{Фن்่o}

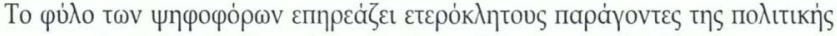

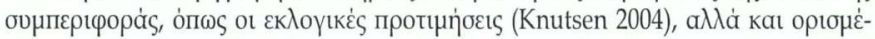

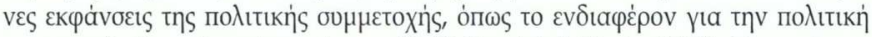

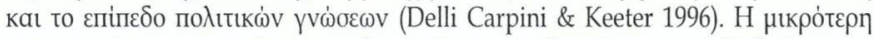

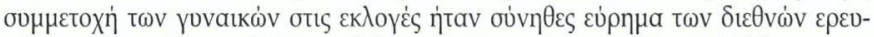

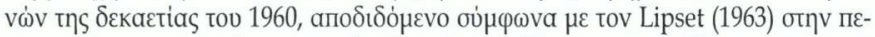

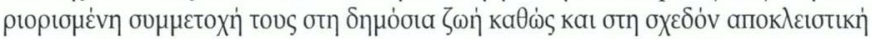
афоoi

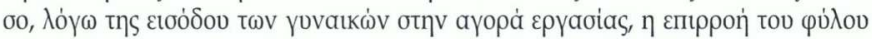

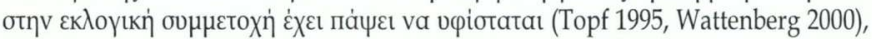

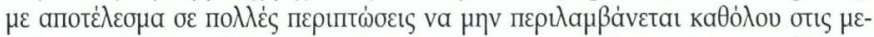

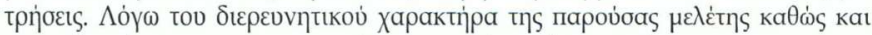

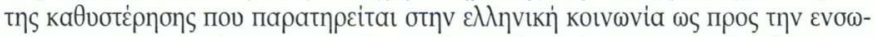

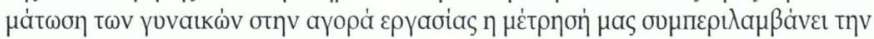

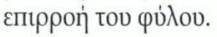

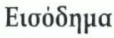

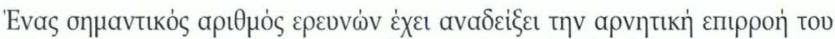

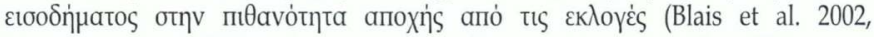

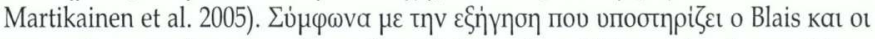

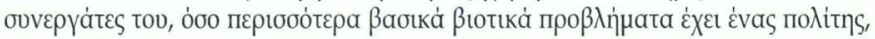

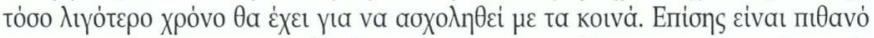

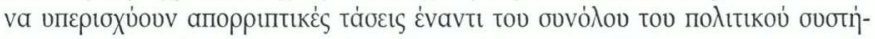

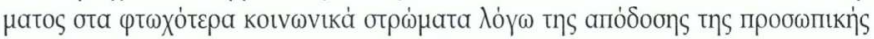

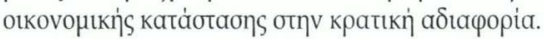




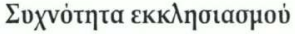

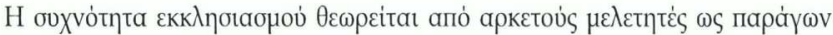

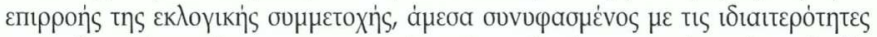

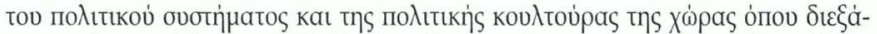

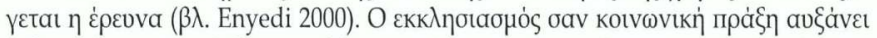

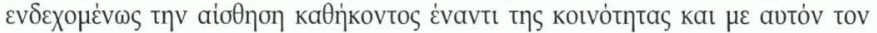
тро́по

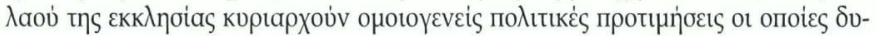

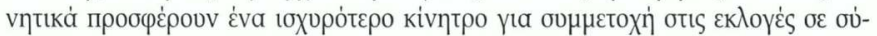

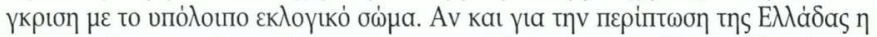

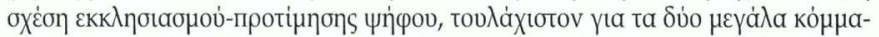

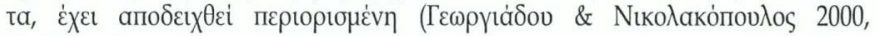

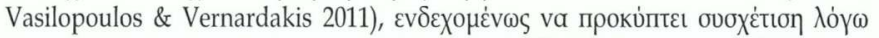

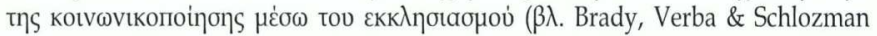
1995).

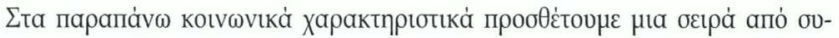

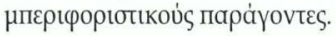

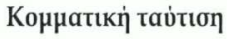

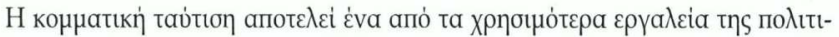

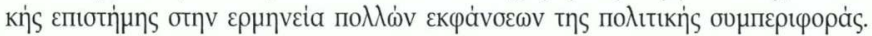

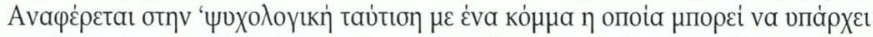
X

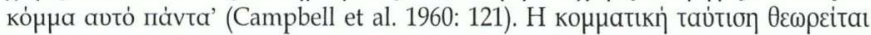

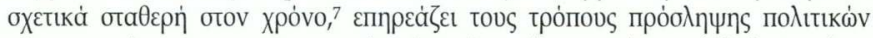

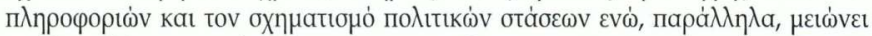

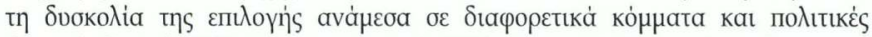

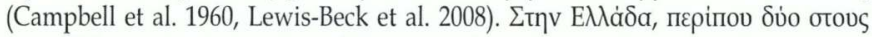

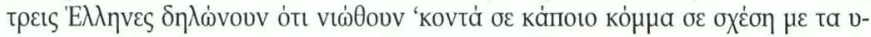
по்

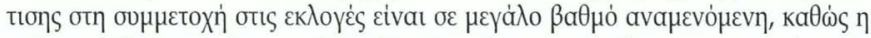

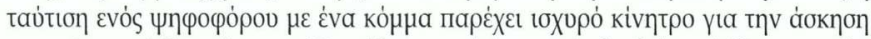

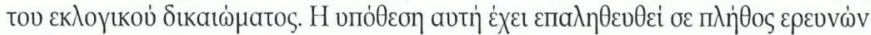

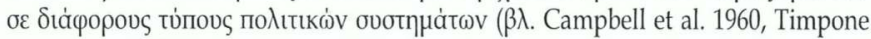

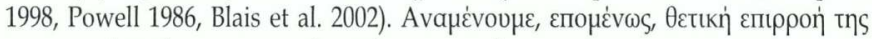

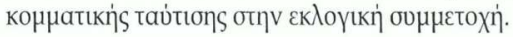




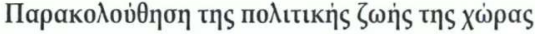

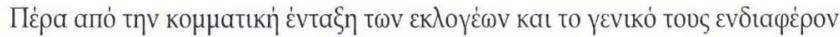

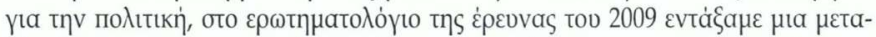

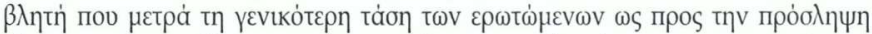

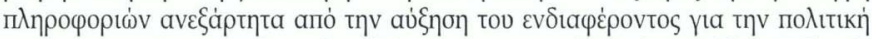

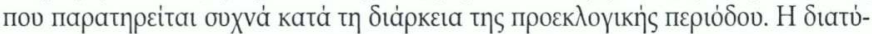

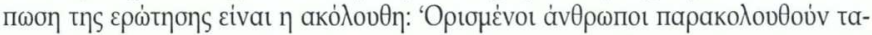

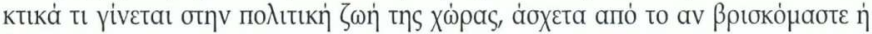

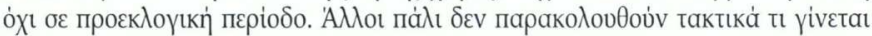

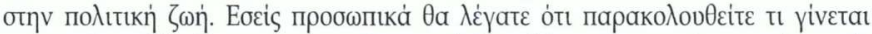

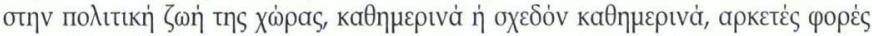

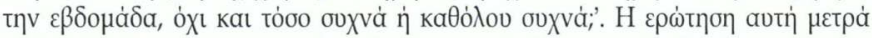

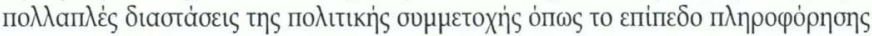

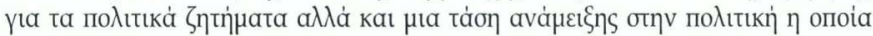

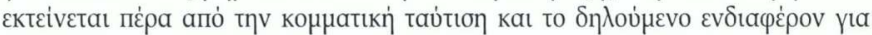

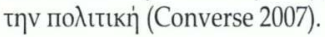

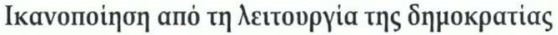

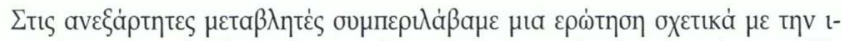

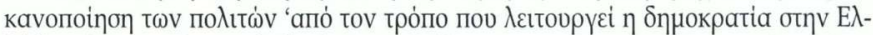

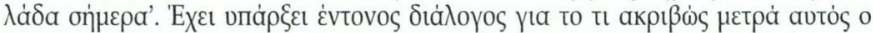

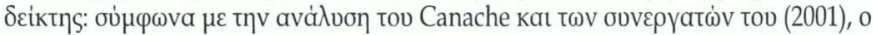

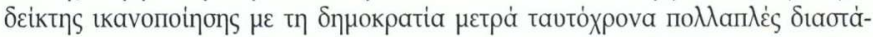

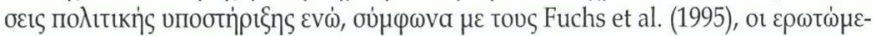

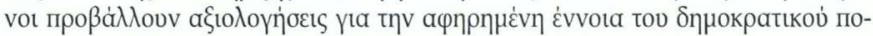

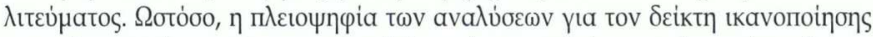

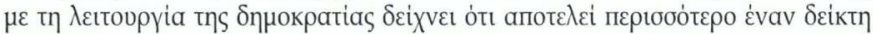

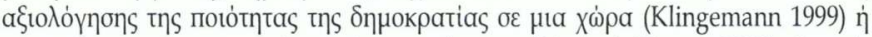

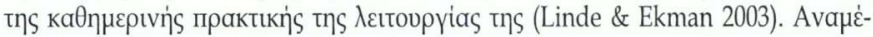

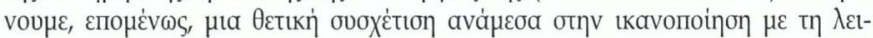

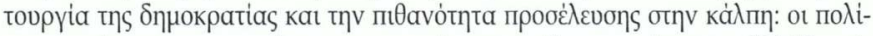

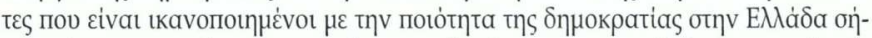

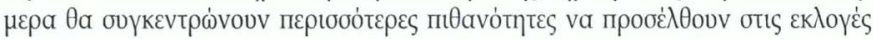

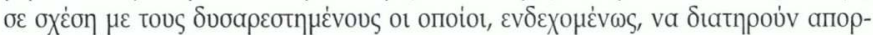

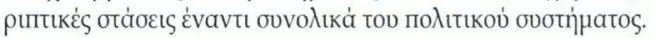

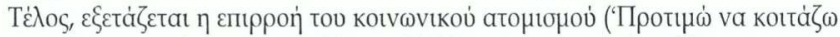

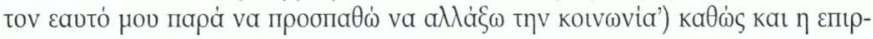




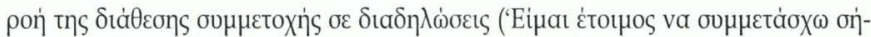

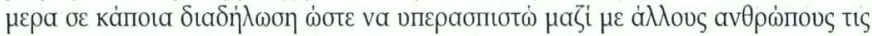

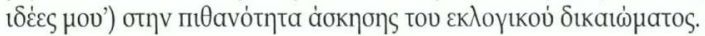

\section{Апотеภغ̇оцата}

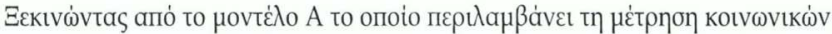

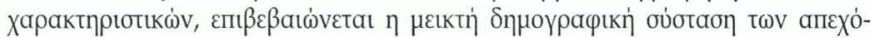

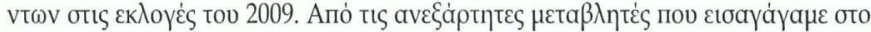

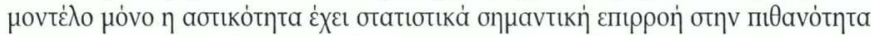

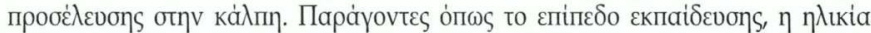

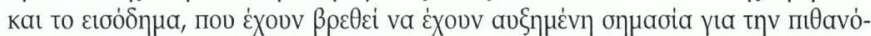
түта апохฑ่

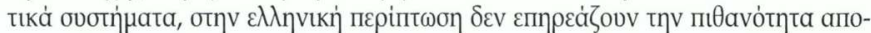

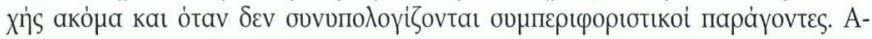

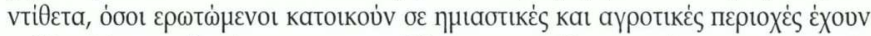

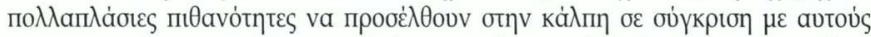

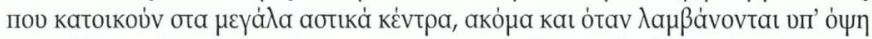

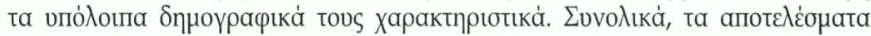

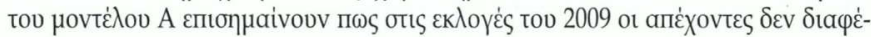

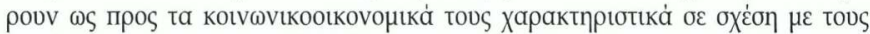

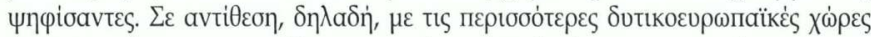

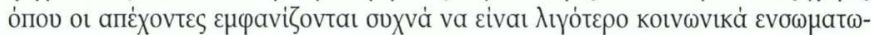

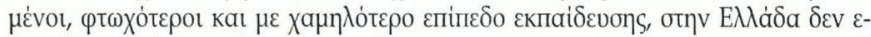

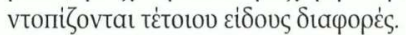

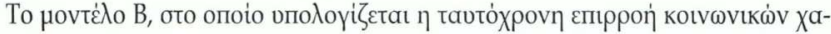

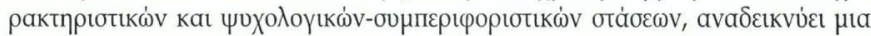

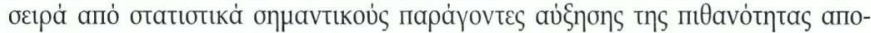

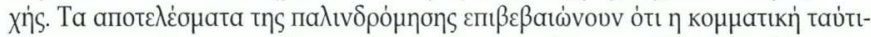

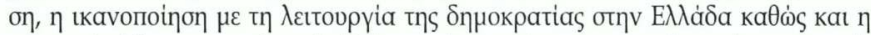

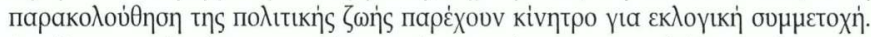

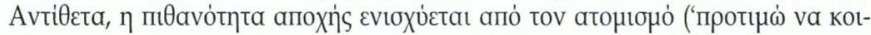

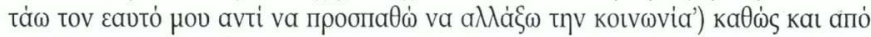

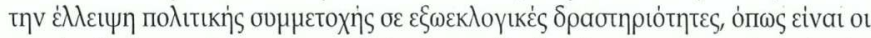

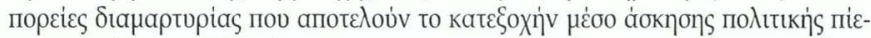

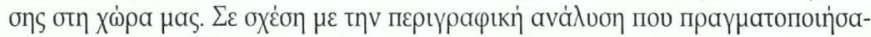

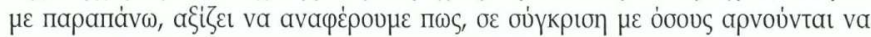

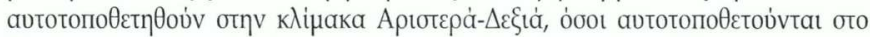

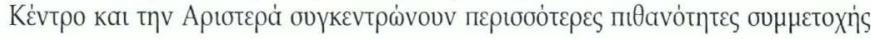




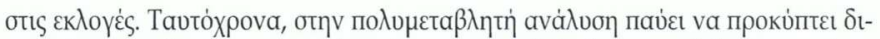

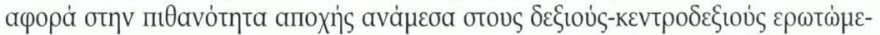

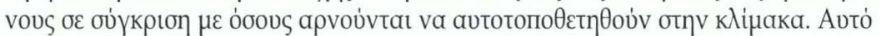

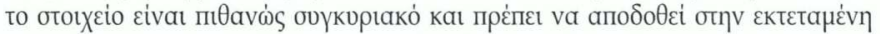

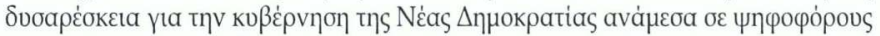

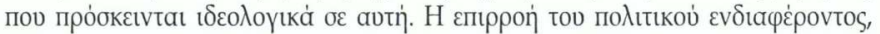

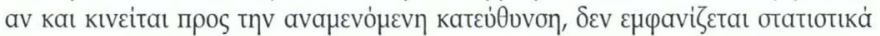

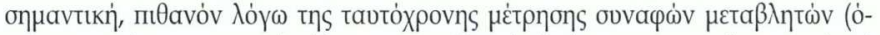

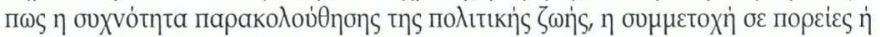

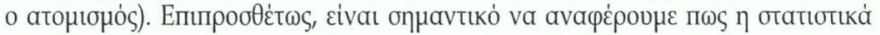

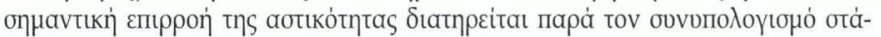

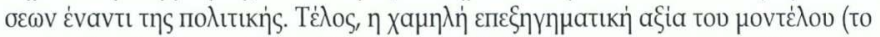

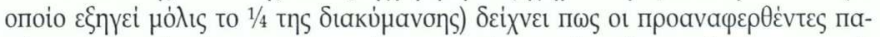

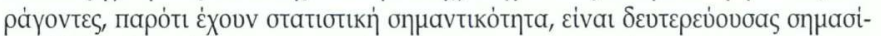

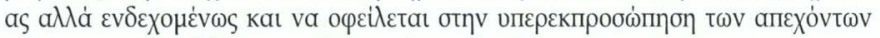

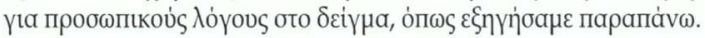

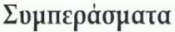

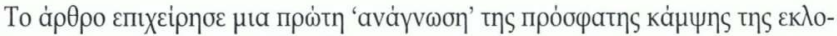

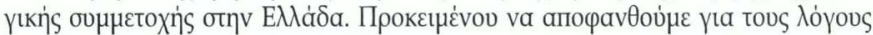

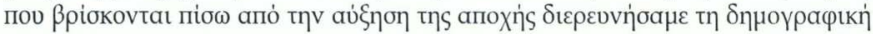

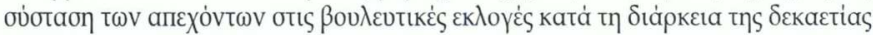

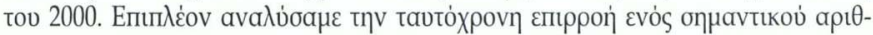

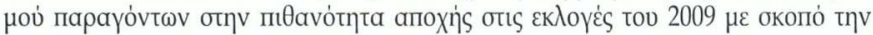

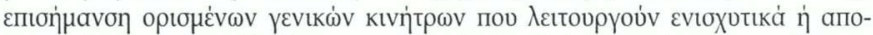

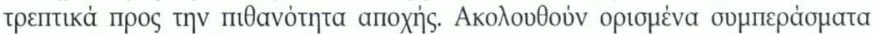

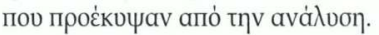

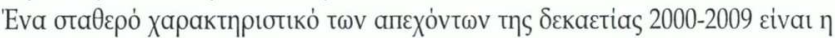

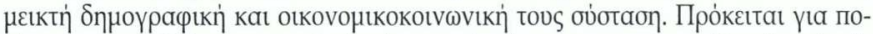

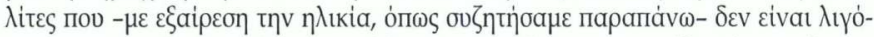

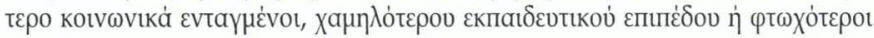

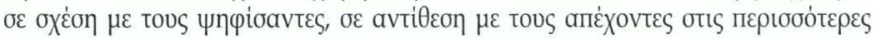

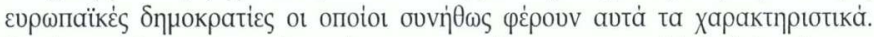

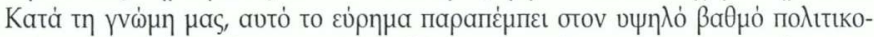

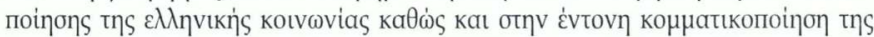

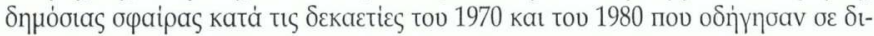

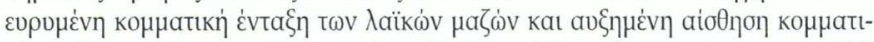

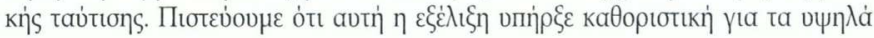




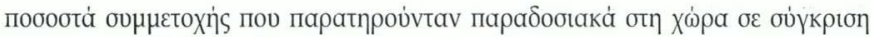

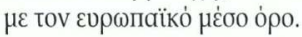

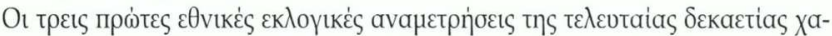

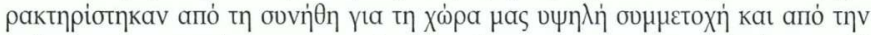

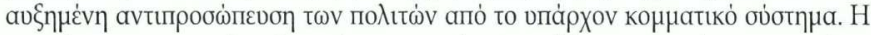

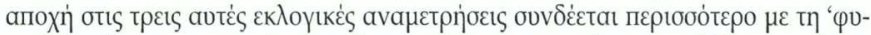

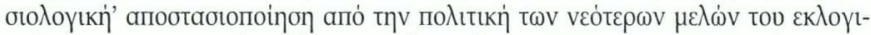

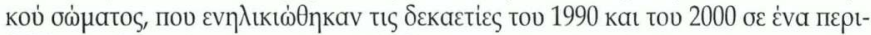

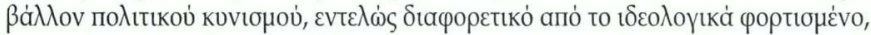

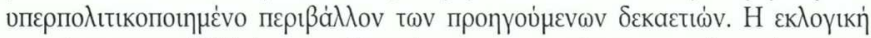

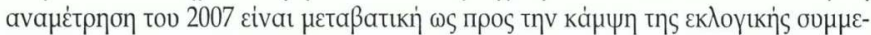

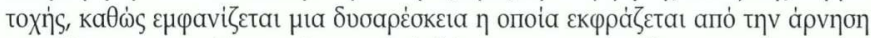

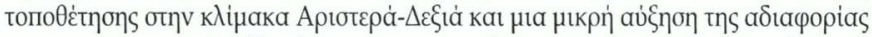

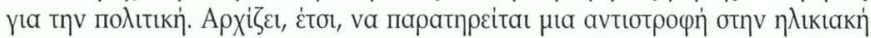

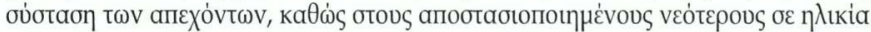

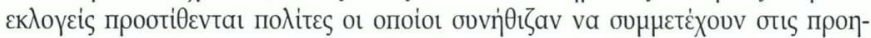

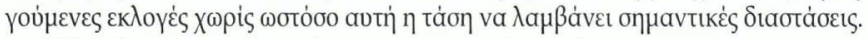

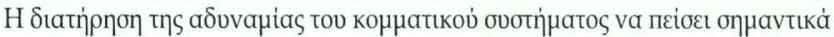

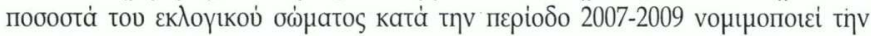

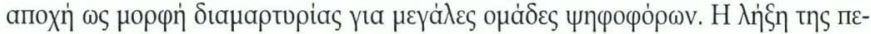

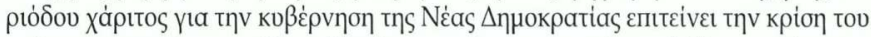

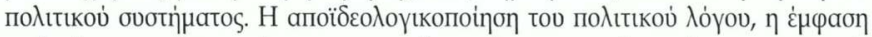

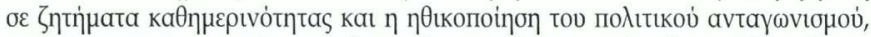

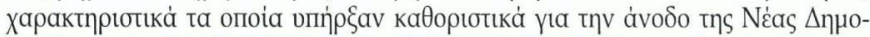

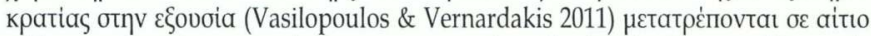

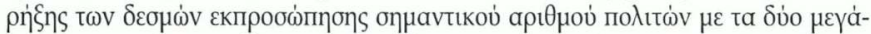

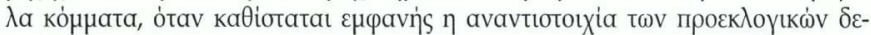

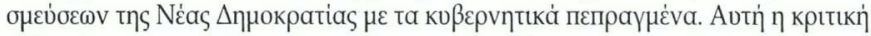

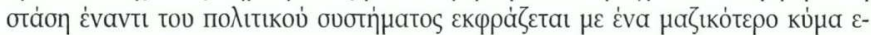

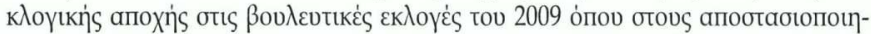

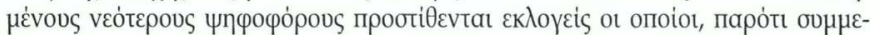

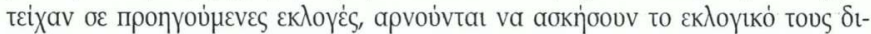

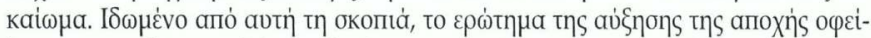

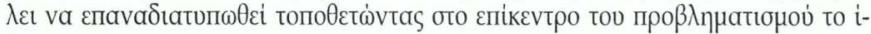

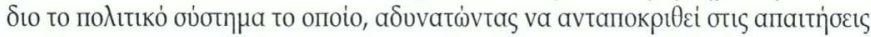

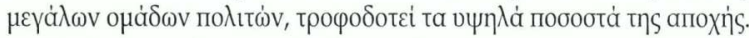

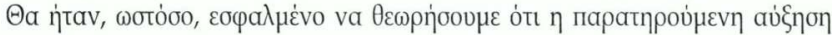

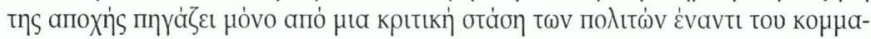




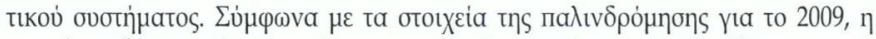

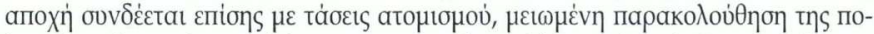

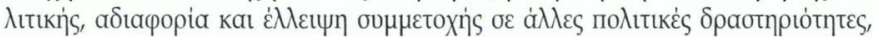

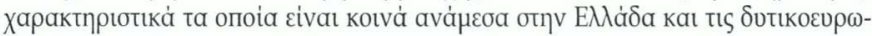

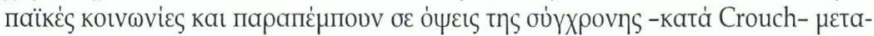

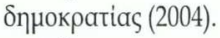

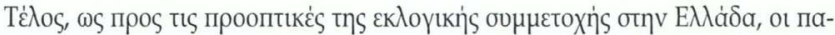

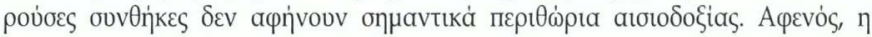

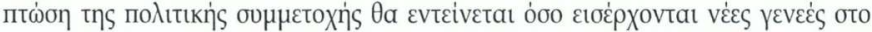

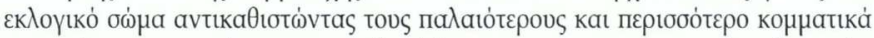

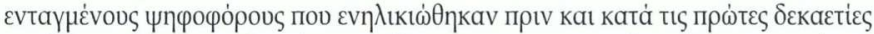

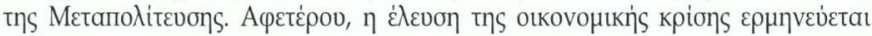

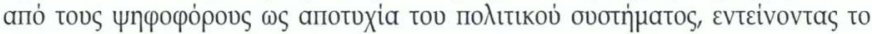

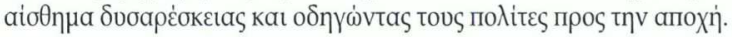

\section{$\Sigma \eta \mu \varepsilon 1 \omega \sigma \varepsilon 1 \varsigma$}

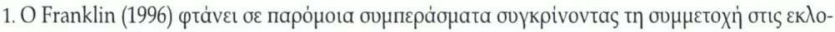

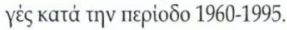

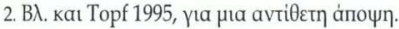

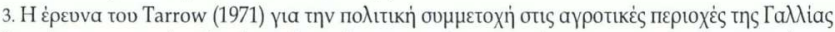

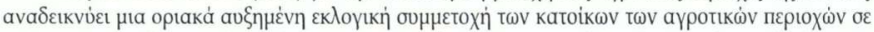

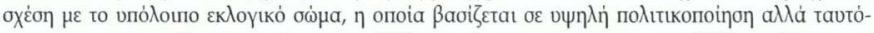

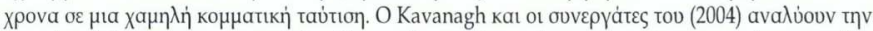

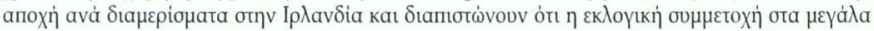

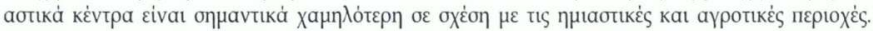

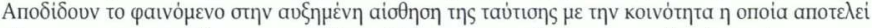

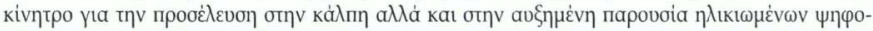

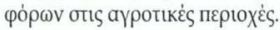

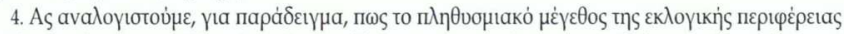

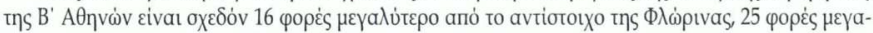

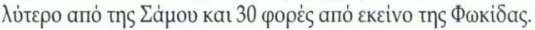

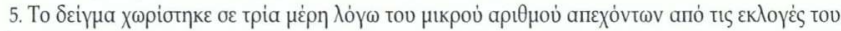
2004.

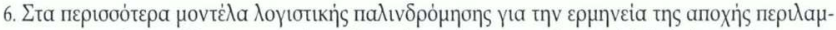

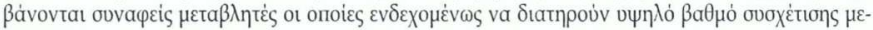

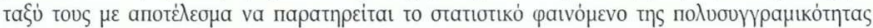

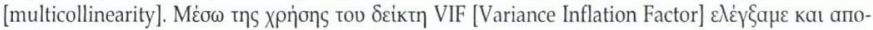

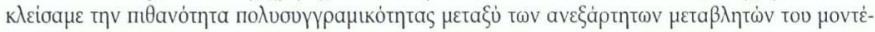

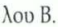




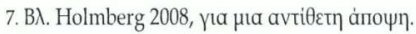

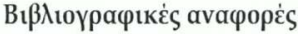

Aarts, K. \& Wessels, B. (2005). 'Electoral turnout', oto Thomassen, J., єпџн., The European Voter: A Comparative Study of Modern Democracies. Oxford: Oxford University Press.

Almond, G.A. \& Verba, S. (1963/1989). The Civic Culture: Political Attitudes and Democracy in Five Nations. London: SAGE.

Blais, A. (2008). 'Turnout in Elections', бто Dalton, R. \& Klingemann, H.D., впц., The Oxford Handbook of Political Behavior. Oxford: Oxford University Press.

Blais, A., Gidengil, E., Nadeau, R. \& Nevitte, N. (2002). 'Generational Change and The

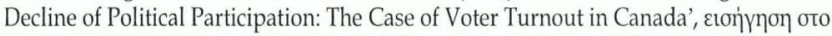
ovvédpto Citizenship on Trial: Interdisciplinary Perspectives on Political Socialization of

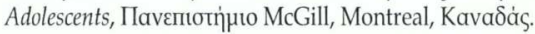

Blais, A., Gidengil, E., Nevitte, N. \& Nadeau, R. (2004). 'Where Does Turnout Decline Come From?', European Journal of Political Research, 43: 221-236.

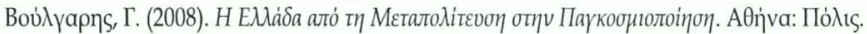

Brady, H.E, Verba, S. \& Schlozman, K.L. (1995). 'Beyond SES: A Resource Model of Political Participation', American Political Science Review, 89 (2): 271-294

Campbell, A., Converse, P., Miller W.E. \& Stokes, D. (1960/1980). The American Voter, London: University of Chicago Press.

Canache, D., Mondak, J.J. \& Seligson, M. (2001). 'Meaning and Measurement in CrossNational Research on Satisfaction with Democracy', Public Opinion Quarterly, 65: 506528.

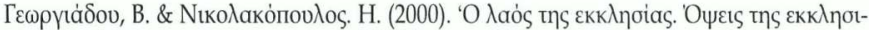
аотเкท่ Ө

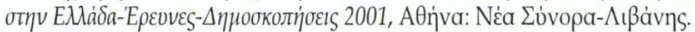

Clarke, H.D., Sanders, D., Stewart, M.C. \& Whteieley, P. (2004). Political Choice in Britain. Oxford: Oxford University Press.

Conover, P. \& Feldman, S. (1981). 'The Origins and Meaning of Liberal /Conservative Self- Identifications', American Journal of Political Science, 25 (4): 617-645.

Converse, P. (2008). 'Perspectives on Mass Belief systems and Communication', oto Dalton, R.J \& Klingemann H-D. (єпเц.), The Oxford Handbook of Political Behavior. Oxford: Oxford University Press.

Crouch, C. (2004). Post- Democracy. Cambridge: Polity Press.

Dalton, R.J. (1984). 'Cognitive Mobilization and Partisan Dealignment in Advanced Industrial Societies', The Journal of Politics, 46 (1): 264-284. 
Delli Carpini, M.X. \& Keeter, S. (1996). What Americans Know about Politics and Why it Matters. London: Yale University Press.

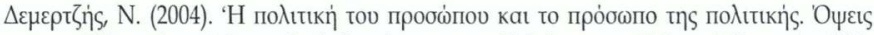

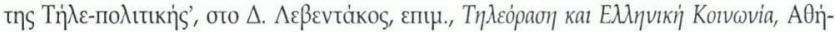
va: Eıкஸ்v.

Eliasoph, N. (1998). Avoiding Politics: How Americans Produce Apathy in Everyday Life. Cambridge: Cambridge University Press.

Enyedi, Z. (2000). 'Religious and Clerical Polarization in Hungary', ото D. Broughton \&

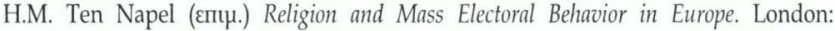
Routledge.

Franklin, M.N. (1996). 'Electoral Participation', ото LeDuc, L., Niemi, R.G. \& Norris, P. (єпц.), Comparing Democracies: Elections and Voting in Comparative Perspective. London: SAGE.

Fuchs, D., Guidorossi, G. \& Svensson, P. (1995). 'Support for Democratic System', ото

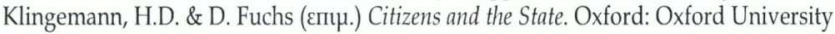
Press.

Gays, B. (2006). 'Explaining Voter Turnout: A Review of Aggregate-Level Research', Electoral Studies, 25: 637-643.

Goerres, A. (2007). 'Why are Older People More Likely to Vote? The Impact of Ageing on Electoral Turnout in Europe', The British Journal of Politics and International Relations, 9 (1): $90-121$.

Granberg, D. \& Holmberg, S. (1991). 'Self- Reported Turnout and Voter Validation', American Journal of Political Science, 35 (2): 448-459.

Granberg, D. \& Holmberg, S. (1992). 'The Hawthorne Effect in Election Studies: The Impact of Survey Participation on Voting', British Journal of Political Science, 22 (2): 240247.

Holmberg, S. (2008). 'Partisanship Reconsidered', oto Dalton, R.J \& Klingemann H-D. (єпц.), The Oxford Handbook of Political Behavior. Oxford: Oxford University Press.

Inglehart, R. \& Klingemann, H.D. (1976). 'Party Identification, Ideological Preference and the Left-Right Dimension among Western Mass Public', oто Budge, I., Crew, I. \& D.

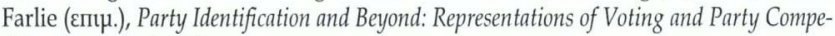
tition. New York: Wiley.

Karamichas, J. (2007). 'The Impact of the 2007 Summer Forest Fires in Greece: Recent Environmental Mobilizations, Cyber-Activism and Electoral Performance', South European Society \& Politics, 12 (4): 521-533.

Kavanagh, A., Mills, G. \& Sinnott, R. (2004) 'The Geography of Irish Voter Turnout: A Case Study of the 2002 General Election', Irish Geography, 37: 177-186. 
Klingemann, H.D. (1999). 'Mapping political support in the 1990s: A global analysis', in Norris, P., eпı.., Critical Citizens: Global Support for Democratic Governance. Oxford: Oxford University Press.

Knutsen, O. (2004). Social Structure and Party Choice in Western Europe: A Comparative Longitudinal Study. New York: Palgrave MacMillan.

Lewis-Beck, M.S, Jacoby, W.G., Norpoth, H., \& Weisberg, H.F. (2008). The American Voter Revisited, Chicago: University of Michigan Press.

Linde, J. \& Ekman, J. (2003). 'Satisfaction with democracy: A note on a frequently used indicator in comparative politics', European Journal of Political Research 42, 391-408.

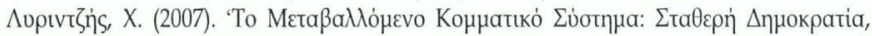

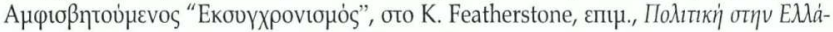

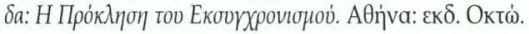

Mair, P. (2007).'Left Right Orientations', ото Dalton, R.J \& Klingemann H-D. (єпин.), The Oxford Handbook of Political Behavior. Oxford: Oxford University Press.

Martikainen, P., Martikainen, T. \& Wass, H. (2005). 'The effect of socioeconomic factors on voter turnout in Finland: A register-based study of 2.9 million voters', European Journal of Political Research, 44: 645-669.

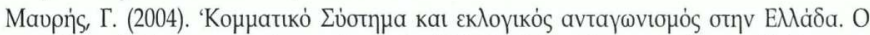

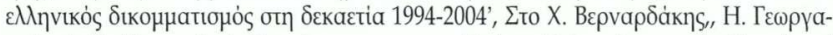

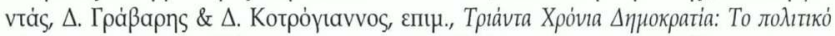

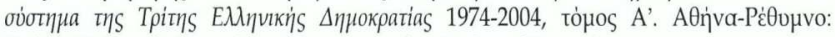

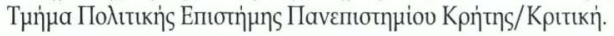

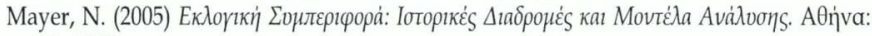
$\Sigma a \beta \beta a \dot{\lambda} a s$.

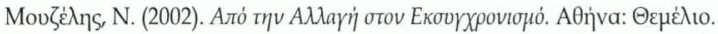

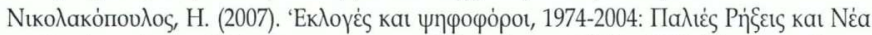

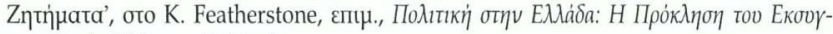

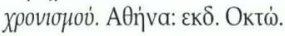

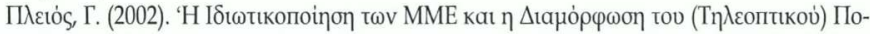

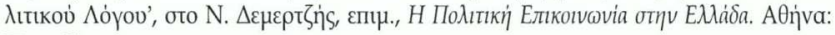

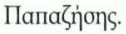

Powell, B.J. (1986). 'American Voter Turnout in Comparative Perspective', The American Political Science Review, 80 (1): 17-43.

Smith, J. (1999). Europe's Elected Parliament. Sheffield: Sheffield Academic Press.

Tarrow, S. (1971). 'The Urban-Rural Cleavage in Political Involvement: The Case of France', American Political Science Review, 65 (2): 341-157.

Timpone, R.J. (1998). 'Structure, Behavior and Voter Turnout in the United States', The American Political Science Review, 92 (1): 145-158. 
Topf, R. (1996). 'Electoral Participation', oro Klingemann, H.D \& Fuchs, D. (єпц..), Citizens and the State. Oxford: Oxford University Press.

Wattenberg, M.P. (2000). 'The Decline of Party Mobilization', oto Dalton, R. \& Wattenberg, M.P. (єпцц.). Parties without Partisans: Political Change in Advanced Industrial Democracies, Oxford: Oxford University Press.

Vasilopoulos, P. \& Vernardakis, Ch. (2011). 'The Rise and Fall of the Greek Conservative Party 2004-2009: Ideological Realignment and Egocentric Economic Voting at the Dawn of the Financial Crisis', paper presented at the $61^{\text {st }}$ Political Science Association Annual Conference, London.

Vernardakis, Ch. (2000). 'Les élections grecques d'avril 2000: Le cas d'un bipartisme convergent', Pole Sud, 13 (13): 145-157.

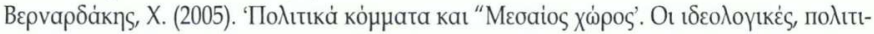

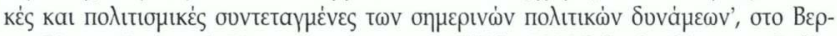

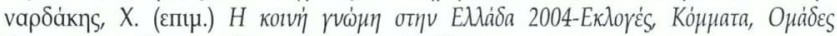

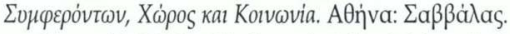

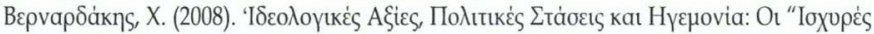

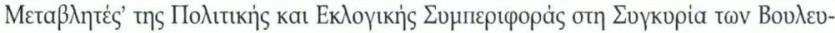

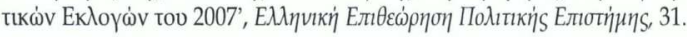

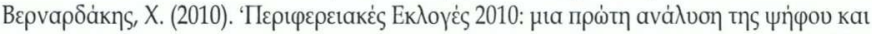

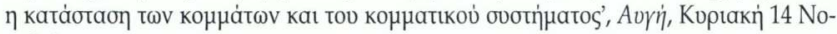

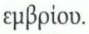

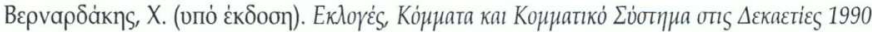

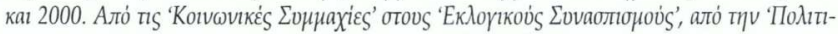

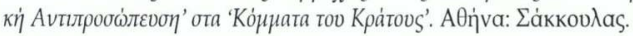

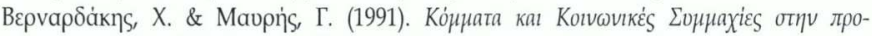

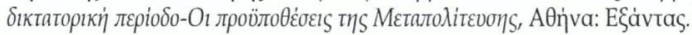

